\title{
Mothering and Stress During COVID-19: Exploring the Moderating Effects of \\ Employment
}

\author{
Hope Xu Yan ${ }^{12}$, Liana C. Sayer ${ }^{2}$, Daniela Veronica Negraia ${ }^{3}$, R. Gordon Rinderknecht ${ }^{4}$, \\ Long Doan ${ }^{2}$, Kelsey J. Drotning ${ }^{2}$, Jessica N. Fish ${ }^{2}$ and Clayton Buck ${ }^{2}$
}

Yan, Hope Xu, Liana C. Sayer, Daniela V. Negraia, R. G. Rinderknecht, Long Doan, Kelsey J. Drotning, Jessica N. Fish, and Clayton Buck. 2022. "Mothering and Stress During COVID19: Exploring the Moderating Effects of Employment." Socius: Sociological Research for a Dynamic World. 8:1-21

${ }^{1}$ Direct all correspondence to Xu Yan (xyan9@terpmail.umd.edu)

${ }^{2}$ University of Maryland, College Park

${ }^{3}$ University of Oxford

${ }^{4}$ Max Planck Institute for Demographic Research 


\begin{abstract}
Using primary data from the Assessing the Social Consequences of COVID-19 study, we examined how the pandemic affected the stress levels of women with and without coresiding minor children (mothers vs. non-mothers), paying special attention to the moderating role of employment status. The OLS regression results show following the pandemic outbreak, among full-time working women, mothers reported smaller stress increases than non-mothers. In contrast, among part-time and non-employed women, mothers and non-mothers experienced similar stress increases. Also, full-time working mothers reported smaller stress increases than women with most other mothering and employment statuses. Changes in women's employment status, following pandemic onset, had limited impacts on the patterns of stress change. This study contributes to research on parenting and health by showing that during times of crisis, full-time employment may be protective of mothers' mental health, but may not buffer the mental health deterioration of women not raising children.
\end{abstract}

Keywords: COVID-19; parenting; women; stress; employment 


\section{Introduction}

The COVID-19 pandemic has disrupted the lives of individuals and families to levels unseen by most contemporary adults (Pew Research Center 2020a, 2020b). Worrying about their health and economic well-being, adults report higher levels of stress compared to pre-pandemic periods (Fitzpatrick, Harris, and Drawve 2020; Salari et al. 2020). These stressful feelings have been exacerbated due to the complete overhaul of people's daily routines by lock-down measures that aimed to curb the spread of the virus (Ingram, Maciejewski, and Hand 2020). Using primary data from the Assessing the Social Consequences of COVID-19 (ASCC) study, our study examines how the pandemic has affected the stress levels of adult women caring and not caring for minor household children (who we refer to as "mothers" and "non-mothers"). Specifically, we explore how mothers' and non-mothers' stress levels changed during the early days of the COVID-19 pandemic relative to pre-pandemic periods, paying special attention to how the association between mothering and changes in stress levels during the pandemic varied by women's employment status.

Despite ideals of shared work and egalitarian family roles, women continue to do most housework and childcare (Bianchi et al. 2000, 2012; Negraia, Augustine, and Prickett 2018). Prior to the pandemic, women can reduce their feelings of time pressure and stress by outsourcing domestic work (Craig et al. 2016; Craig and Churchill 2018). During the pandemic, when life is mostly confined to home and the ability to outsource housework and childcare is severely curtailed, women are likely to juggle more responsibilities and experience significant stress increases. However, mothers and non-mothers may have experienced different levels of stress changes following the pandemic outbreak. Pre-pandemic studies suggest that mothers enjoy certain child care activities but also report greater stress than women not raising children (Glass, Simon, and 
Andersson 2016; Musick, Meier, and Flood 2016; Negraia and Augustine 2020; Nomaguchi and Milkie 2017; Umberson, Pudrovska, and Reczek 2010). During the pandemic, mothers may experience greater stress increases than non-mothers due to school closures and increased child care demands (Heggeness and Fields 2020). However, the opposite may also be true if mothers enjoy spending more meaningful time at home with children, whereas non-mothers are stressed by social isolation and decreased sources of emotional support (Gallagher and Gerstel 2001; Kalmijn 2012; Nomaguchi and Milkie 2003).

We pay special attention to how women's paid work hours and employment status moderate the relationship between mothering and stress changes during the pandemic. Prior work has shown that pre-pandemic, full-time employment is beneficial to women's mental health (Caputo, Pavalko, and Hardy 2020; Frech and Damaske 2012; Meier et al. 2016; Pavalko and Smith 1999; Ross and Mirowsky 1995). But long working hours and limited work schedule control can fuel work-family conflicts, hence affecting the stress levels of women raising children (Carrillo et al. 2017; Marshall and Tracy 2009; Milkie, Nomaguchi, and Schieman 2019; Roxburgh 2012). Therefore, changes in women's work and family lives during the pandemic are likely to have distinct effects on the stress levels of mothers and non-mothers with different employment statuses.

We focus on women's stress levels because stress is a predictor of other mental health outcomes such as anxiety and depression (Hammen 2005; Pearlin 1999; Wheaton and Montazer 2009). Stress indicators have also been widely used to study the impacts of mothering and employment on women's well-being (for a review, see Nomaguchi and Milkie 2020), making our results comparable and informative to previous findings.

Using primary data collected during the early days of the pandemic, our paper provides empirical evidence on how the pandemic has influenced the stress levels of women with different 
motherhood and employment statuses. This knowledge contributes to our understanding of the mental health consequences of the COVID-19 restrictions and informs efforts to protect women's mental health during times of crisis. Also, changes in women's work and family lives during the pandemic provide opportunities to better explore the costs and benefits of mothering, and understand how paid employment influences women's feelings of stress.

\section{Background}

\section{Linkages Between Parenting and Stress}

Pre-pandemic Studies on Parenting and Stress. Despite popular beliefs among U.S. adults that raising children brings fulfillment and happiness to people's lives (Hansen 2012), empirical research depicts the parenting role as a "mixed bag" of both "demands and rewards" for adults' well-being (Nomaguchi and Milkie 2020). Parenting can be a source of positive self-worth and happiness in adults' lives in part because parenting offers adults opportunities to pursue valuable goals such as providing care and education to children (Nelson, Kushlev, and Lyubomirsky 2014). Children can also be enjoyable to be around. Recent time-use and well-being research has found that parents perceive their time with children as meaningful, and the happiest of their day (Musick et al. 2016; Nelson et al. 2013; Offer 2014). However, parenting also brings about demands and challenges, linked to the emotional, time, and financial commitments of raising children, which can be a source of stress (Negraia and Augustine 2020; Pollmann-Schult 2014). On average, both mothers and fathers fare worse than adults not raising children across dimensions of mental health outcomes such as stress, fatigue, depression, and overall life satisfaction (Glass et al. 2016; Margolis and Myrskylä 2011; McLanahan and Adams 1987; Negraia and Augustine 2020; Umberson et al. 2010). The costs of parenting to adults' emotional well-being are higher for 
mothers than for fathers (Musick et al. 2016; Offer 2014) because women continue to be the primary caregiver and take on more stressful activities like routine childcare (i.e., feeding, bathing, and dressing) than men do (Musick et al. 2016; Negraia, Yavorsky, and Dukhovnov 2020). Further, the ideologies of "intensive mothering" and "concerted cultivation" also make mothering increasingly stressful. By emphasizing mothers' formative role in children's development and well-being, these mothering ideologies encourage activities that demand high levels of energy and time such as organizing children's extracurricular activities, providing emotional support to children, and making sacrifices to meet children's needs (Gunderson and Barrett 2017; Hays 1996; Lareau 2011; Nomaguchi and Milkie 2020; Rizzo, Schiffrin, and Liss 2013).

Parenting and Stress during COVID-19. Recent studies have observed an increase in stress during the COVID-19 pandemic within the general population and among adults raising children (Gassman-Pines, Ananat, and Fitz-Henley 2020; McGinty et al. 2020). However, little is known about whether and how the impacts of the pandemic on women's stress levels may vary between mothers and non-mothers. Because mothering role is associated with both rewards and demands for adults' well-being, the abrupt changes to individuals' daily routines brought on by the COVID19 pandemic may differently impact the stress levels of mothers and non-mothers.

For mothers, the closures of care facilities and schools can lead to growing demands of childcare and homeschooling, which may cost mothers more time and energy, potentially leading to greater stress for them. Mothers spending more time with children may also increase opportunities for parent-child conflicts (Evans et al. 2020). However, it is also possible for the pandemic to amplify the fulfillment and happiness that mothering brings because spending more meaningful time at home with children during social distancing may shelter mothers from social isolation related stress (Evans et al. 2020; Heggeness and Fields 2020; Kochhar 2020). Further, 
some of the stressors associated with intensive mothering practices such as chauffeuring, attending children's events, and arranging playdates may decline as extracurricular activities, social events, and gatherings come to a halt.

Women not raising children do not experience the stress of growing childcare demands during the pandemic. Yet, they may still experience greater stress increases relative to mothers due to the lack of family and social support. Parenting enables adults to strengthen their ties with extended family members and neighbors who can provide help in times of need (Gallagher and Gerstel 2001; Kalmijn 2012; Nomaguchi and Milkie 2003). Therefore, compared to mothers, the pandemic and stay-at-home orders may set more restrictions on the emotional and social support available to non-mothers. Moreover, during pre-pandemic periods, non-parents enjoyed more leisure time (which is a source of positive emotions) than parents (Claxton and Perry-Jenkins 2008; Sayer 2016). However, because the pandemic closed restaurants and entertainment venues, and put limits on outings with friends, non-mothers may have fewer sources of positive emotions.

\section{Linkages between Mothering, Employment, and Stress}

Pre-pandemic Studies on Parenting, Employment, and Stress. Participating in paid employment is found to benefit women's mental health by providing a source of income, space to develop one's social network, and a sense of self-worth (Caputo et al. 2020; Frech and Damaske 2012; Pavalko and Smith 1999; Ross and Mirowsky 1995). But employment types and job characteristics matter. Jobs characterized by low control such as most part-time jobs, or high demands such as selfemployment may reduce feelings of self-efficacy and increase stress (Davis et al. 2008; Melchior et al. 2007). By contrast, full-time jobs can usually provide more resources such as higher pay, more autonomy, and schedule flexibility, all of which bring about more benefits for women's longterm well-being (Frech and Damaske 2012). 
Among women raising children, evidence on associations between employment type and stress is mixed. Some studies have found that employed mothers report lower stress than nonemployed mothers (Buehler and O'Brien 2011; Meier et al. 2016; Nomaguchi and Brown 2011; Nomaguchi and Johnson 2016). However, employment is also a source of stress for mothers. In the U.S., the hegemonic motherhood ideology and ideal worker norm position employment and motherhood as contradictory to each other (Blair-Loy 2003; Dow 2016; Hays 1996; Moen and Roehling 2005). Parenting and working are, therefore, competing for mothers' limited resources, leading to work-family conflicts. Long work hours, blurred boundaries between work and nonwork time, and limited control over work schedules all result in high stress for mothers (Carrillo et al. 2017; Kelly et al. 2014; Milkie et al. 2019; Roxburgh 2012).

Parenting, Employment, and Stress during COVID-19. The COVID-19 pandemic has triggered significant changes in women's work and family life. Many employed women, especially those who were employed full-time in high income jobs, are now working remotely from home (Pew Research Center 2020). Working from home may to some extent alleviate work-family conflicts caused by long commutes and schedule conflicts between mothers and children. Transitioning into remote working during the early days of the pandemic may have also temporarily decreased mothers' workloads, allowing them to spend more time with their children. However, as children spend more time at home, mothers are likely to struggle even more to find a balance between their competing responsibilities, which now include not only their own job, housework, and childcare, but also homeschooling. During early days of the pandemic, about 37 percent of mothers parenting children younger than 12 found it difficult to handle childcare responsibilities (Pew Research Center 2020). This percentage is likely to be higher for mothers who continued working for pay during the pandemic. Yet, as mentioned above, paid employment, 
especially full-time employment, can provide women with material, psychological, and social resources that benefit their mental health. These resources may help working mothers cope with the sudden life changes and stress increases brought by the pandemic.

For non-mothers, working during the pandemic may be more stressful compared to the prepandemic era if they can no longer tap into the social support and leisure activities that they used to rely on for coping with work related stress. Yet, not working or experiencing reduced work hours during the pandemic may also exacerbate non-mothers' feelings of social isolation, hence increasing their stress levels.

Despite the rapid increase of remote working, not all jobs can be done at home. People with lower education and income are less likely to work from home than their more privileged counterparts (Pew Research Center 2020). This means many women, especially those doing lowskilled part-time jobs, may still need to be physically present at the workplace and bear the risk of infection. Further, the unemployment caused by social distancing has largely impacted sectors and occupations disproportionately held by women (Alon et al. 2020; Landivar et al. 2020). In direct response to the pandemic, many mothers also left jobs or reduced their work hours to cope with increasing domestic and childcare demands (Collins et al. 2021; Landivar et al. 2020). Experiencing financial loss due to reduced work hours or working with high infection risks may cause greater stress increases for mothers than for non-mothers because besides worrying about themselves and family members' well-being, mothers also face the emotional toll of not providing for children's needs and putting children's health in danger.

\section{The Present Study}

This study sets out to examine the impacts of the COVID-19 pandemic on women's stress levels at the intersection of parenting and employment status. Drawing on the previous literature, we 
anticipate that both mothers' and non-mothers' stress levels have changed following the onset of the pandemic. We expect changes in the level of stress that mothers and non-mothers have experienced to vary by their employment status. However, we remain agnostic about the expected direction of these changes because, as discussed above, the impacts of the pandemic on mothers' and non-mothers' work and family lives are complex, on-going, and yet to be fully understood. For this reason, we do not formulate formal hypotheses, but raise the following research questions:

1. Have stress levels of adult women raising minor children, and those not raising minor children, changed during the COVID-19 pandemic compared to pre-COVID-19 periods? If so, how?

2. Does the association between mothering and change in stress during the COVID-19 pandemic vary by women's employment conditions?

\section{Data and Methods}

\section{Data}

We used data from the second wave of the Assessing the Social Consequences of COVID-19 (ASCC) study, which is part of a larger project that collects information on Americans' social behaviors and attitudes before, during, and after the COVID-19 pandemic. Respondents were recruited using Prolific (www.prolific.co), a crowdsourcing platform used by scholars and market analysts to recruit study participants. Although the sample is not nationally representative, a selfadministered online survey using a crowdsourcing platform allowed us to collect data immediately following the pandemic outbreak when people's lives were disorganized and conventional ways of data collection were disrupted. Also, Prolific has been found to produce high quality data using 
traditional metrics such as satisficing and attention checks, and the sample's ability to reproduce well-documented effects in prior studies (Peer et al. 2017).

We used the second wave of the study because it contains a larger sample size compared to the first wave, allowing us to conduct more detailed statistical analyses. The second wave of ASCC collected data from 3,108 respondents between April 7 and May 15, 2020. We restricted the sample to women aged 18 to 49 years old $(\mathrm{N}=1,581)$ to limit the share of non-mothers who might be empty nesters (i.e., having grown children living outside the home; a limitation shared by other studies on mothers' well-being such as Glass et al. 2016). We also tested two different sample specifications, one limited to women aged 18 to 44 and one limited to women aged 18 to 39. Results were similar across all three sample specifications. The variables we used had a small amount of missing data (ranging from 0.06 to 2.40 percent). Applying the listwise deletion method and using the multiple imputation technique with five replicates of the dataset generated similar results (Allison 2001). We present the results using the listwise deletion method. The final study sample consisted of 1,505 women: 365 women living with their own minor children (mothers), and 1,140 women who did not coreside with their own minor children (non-mothers).

\section{Measures}

Dependent Variables: Women's Stress Levels. We employed three outcome measures to capture respondents' self-reported stress levels prior to the COVID-19 pandemic, during the COVID-19 pandemic, and the change in stress levels between these two periods. The ASCC study adopted the stress measurement method used since 2007 by the American Psychological Association's annual "Stress in America" survey (APA 2021). Respondents were asked: "On a scale of 0 to 10, with 0 being no stress and 10 being the worst stress possible, what number best describes your level of stress prior to the COVID-19 pandemic (Time 1) and currently (during the COVID-19 
pandemic, Time 2)". Using these two measures of respondents' stress levels, we then calculated an indicator for the changes in women's stress levels after the pandemic outbreak (Time 2 - Time 1); positive values indicated an increase in women's stress levels. Due to data limitations, prepandemic stress levels could only be obtained through retrospection ${ }^{1}$. Respondents' retrospective reports of pre-pandemic stress might be influenced by their experience during the pandemic (Mill, Realo, and Allik 2016). This is a limitation faced by many studies that explore COVID-19's impacts on mental health (for example, Adams et al. 2021; Uehara, Fujii, and Kobayashi 2021). However, because in the ASCC, respondents reported their pre-pandemic and during-pandemic stress levels at the same time, the data should be able to capture their own perceptions of how their stress levels have changed following the pandemic onset, which is the key focus of this study. Also, consistent with existing studies' findings on social determinants of stress (Turner and Turner 2005; Turner, Wheaton, and Lloyd 1995), we found respondents reported significantly lower prepandemic stress when they were men, older, married, not parenting children under 18 , and had higher household income (results not presented). Therefore, the retrospective reports of stress should still reflect respondents' stress levels before the pandemic outbreak.

Independent Variables. Our first key independent variable was women's parenting status, operationalized as 1= "mothers" if women reported living with non-adult children of their own, and $0=$ "non-mothers" if they reported not living with minor children of their own during the pandemic. The second independent variable was women's employment conditions, captured first using a categorical measure of weekly work hours during the pandemic: $0=$ "35 hours or more" (working full-time); 1= "1-34 hours" (working part-time); $2=$ "0 hours" (not working for pay). We also used an indicator of women's employment status during the pandemic, coded into five mutually exclusive categories: 1= "full-time", $2=$ "part-time", $3=$ "self-employed", $4=$ 
"furloughed", and 5= "unemployed/not in the labor market (including retired, disabled, stay-athome, and unemployed/not in the labor force)". The weekly work hour variable had the advantage of capturing women's actual workloads during the pandemic, particularly among self-employed women. But it might not distinguish the difference between working 0 hours per week due to being furloughed and non-employed, or the ways full-time, part-time, and self-employed jobs differed in benefits, autonomy, and schedule flexibility as discussed above. The employment status variable provided a complementary measure of women's employment conditions. However, due to the small sample size of mothers who were self-employed (30), and furloughed (22), the results needed to be interpreted with caution. We, therefore, used both weekly work hours and employment status to measure women's employment. We also constructed a variable measuring the change in women's work hours after the pandemic outbreak, based on the difference between women's weekly work hours before and during the pandemic: 1= "always worked full-time", $2=$ "always worked part-time", 3= "always non-employed", 4= "from full-time to part-time or non-employed"”, $5=$ "from part-time to non-employed", and $6=$ "from part-time or non-employed to full-time employed". We did not present results for the last category because the small sample size of this group (26 non-mothers and 5 mothers) made the validity of the results questionable.

Covariates. Models included relevant covariates for women's age and racelethnicity (White, Hispanic, Black, Asian, and Other) as age is negatively associated with stress (Turner and Turner 2005) and mothers in the sample were older than non-mothers (Table 1). Also, compared with White women, women of color are more negatively affected by the pandemic and experience greater increases in stress (Laster Pirtle and Wright 2021; Stockman, Wood, and Anderson 2021). Because socioeconomically disadvantaged people are found to suffer disproportionally from mental health problems during the pandemic (Bambra et al. 2020; Manville et al. 2020), we also 
controlled for women's pre-pandemic employment status (full-time, part-time, self-employed, furloughed, and unemployed/not in the labor force), years of education, annual household income (lower than 20k, 20k-60k, 60k-100k, and higher than 100k), change in family income following the pandemic outbreak (decreased, stayed the same, and increased), home ownership (own with mortgage, own in full, and rented or occupied), and occupation $^{\mathbf{3}}$. We also controlled for women's marital status before and during the pandemic (married/not married), the number of children they have aged between 0-5, 6-12, and 13-174, whether women coresided with a spouse/partner, parents/siblings, or roommates/friends/others (yes/no), as well as spouse/partner's employment status (coded as no spouse/partner when women did not have spouse/partner) before and during the pandemic.

The second wave of ASCC did not directly ask whether respondents could work remotely/from home during the pandemic. But about 65 percent of the respondents completed timeuse diaries. Based on this time-use information we created a measure of work from home coded as $0=$ "did not work from home" (spent less than 20 percent of paid employment time at home); $1=$ "worked from home" (spent 80 percent or more of paid employment time at home); 2= "no information" (cases where no time-use data was available or no paid employment time was reported). Information on working from home was available for 47 percent of the sampled employed women, within which around 78 percent of non-mothers and 81 percent of mothers reported being able to work from home. These estimates are slightly higher than the 71 percent reported by the Pew Research Center in October 2020 (Parker, Horowitz, and Minkin 2020).

\section{Analytic Strategies}

The first aim of this paper was to compare how mothers' and non-mothers' stress levels changed during the COVID-19 pandemic relative to pre-pandemic periods. To do so, we ran ordinary least 
squares (OLS) regression models with women's parenting status as the key independent variable. We ran the models three times to predict each of our dependent variables: 1) women's stress levels before the pandemic, 2) during the pandemic, and 3) the change in their stress levels after the pandemic outbreak. The second aim of this project was to explore how the association between mothering and stress changes varied by women's employment status. We did so by including interaction terms between women's mothering status and their 1) weekly work hours, 2) employment status during the pandemic, and 3) change in work hours after the pandemic outbreak in three separate OLS regression models. The analysis was conducted in STATA 17.

To make the ASCC sample more representative of the U.S. population, we used the iterative proportional fitting (raking) method (Kolenikov 2014) to weight the ASCC data based on the age, race, education level, marital status, employment status, and household income of mothers and non-mothers in the nationally representative 2018 General Social Survey (GSS) (see Appendix A for sample characteristics of the GSS, and the unweighted and weighted ASCC). The results of unweighted and weighted analysis were similar. We present the unweighted models in the results section. The weighted models are in the Appendix and discussed in the text.

\section{Results}

\section{Descriptive Statistics}

Table 1 presents unweighted and weighted descriptive statistics. Without controls described above, mothers reported lower stress levels than non-mothers before and during the pandemic, likely because mothers were older and more socioeconomically advantaged compared to non-mothers. The level of stress increases that mothers and non-mothers experienced during the pandemic were similar. Regarding employment conditions, when unweighted, the work hours and employment 
status of mothers and non-mothers during the pandemic were similar. The weighted statistics show that mothers were less likely to work full-time and more likely to work part-time or be unemployed/out of the labor force than non-mothers during the pandemic. We also found from the unweighted statistics that around 61 percent (about 70 percent if weighted) of mothers and nonmothers maintained pre-pandemic employment status, and about 35 percent (around 30 percent if weighted) of them switched from working full-time to working part-time/not working, or from working part-time to not working.

Compared with the nationally representative 2018 wave of the GSS, women in the ASCC study were less likely to be mothers, and were more highly educated and likely to work for pay before the pandemic outbreak (Appendix A). Further, the ASCC sample captured a smaller proportion of Black women, but a larger proportion of women from other racial minority groups than the GSS sample. Finally, non-mothers in the ASCC were, on average, about four years younger and less likely to be married relative to those in the GSS. The weighted ASCC sample shared similar sociodemographic characteristics with the GSS sample (Appendix A).

[Insert Table 1 about here]

\section{Mothering and Stress Changes During the COVID-19 Pandemic}

Results from the unweighted (Model 1 and 2 in Table 2) and weighted (Model 1 and 2 in Appendix B) OLS regression models show no significant differences between the stress levels of mothers and non-mothers before or during the pandemic ${ }^{5}$. When using the change in women's stress levels following the pandemic outbreak as the dependent variable, we still found no significant difference between mothers and non-mothers in unweighted (Model 3 in Table 2) and weighted (Model 3 in Appendix B) models.

[Insert Table 2 about here] 


\section{Mothering, Employment, and Stress Changes During the COVID-19 Pandemic}

Next, we tested if the relationship between women's mothering status and their levels of stress change was conditioned by employment status. First, we show results from the unweighted OLS regression model where we included an interaction term between women's mothering status and weekly work hours during the pandemic (Model 1 in Table 3). To better present the different stress changes that women with different mothering statuses and weekly work hours had experienced, we calculated predicted means (Figure 1). Among women whose weekly work hours were 35 or more (working full-time) during the pandemic, mothers experienced a 0.29 -unit increase in stress compared with the pre-pandemic era, which was significantly lower than the 1.11-unit increase that non-mothers experienced. Compared with full-time working women, the stress changing patterns for women who worked fewer than 35 hours per week (working part-time) or did not work for pay during the pandemic were significantly different. Among them, mothers and non-mothers experienced similar increases in stress following the pandemic onset. Similar results were observed in the weighted model (Model 1 in Appendix C). Also, the stress increase that full-time working mothers reported was significantly smaller than that of mothers with other employment statuses, and marginally significantly smaller $(\mathrm{p}=0.087)$ than that of non-mothers who did not work for pay (Model 1 in Appendix D).

[Insert Table 3 and Figure 1 about here]

We also ran the model with an interaction term between women's mothering status and a more detailed measure of employment status, contrasting women who were: full-time employed, part-time employed, self-employed, furloughed or unemployed/not in the labor force. The results were similar to those obtained from the model examining the effects of weekly work hours. The unweighted model (Model 2 in Table 3 and Figure 2) shows full-time employed mothers reported 
significantly smaller increases in stress during the pandemic than full-time employed non-mothers. A similar stress changing pattern was observed among furloughed mothers. Whereas among women who were part-time employed, self-employed, or unemployed/not in the labor force, mothers and non-mothers experienced similar increases in stress. Results were similar when using the weighted data for analysis (Model 2 in Appendix C), but the stress changing pattern for selfemployed women was instead similar to that of full-time employed and furloughed women. Due to the small sample size of mothers who were self-employed (30), and furloughed (22), the results should be interpreted with caution.

\section{[Insert Figure 2 about here]}

Lastly, we present results from models where we examined the effects of the change in women's work hours before and during the pandemic, more specifically among women who: always worked full-time, always worked part-time, always non-employed, changed from full-time to part-time/non-employed, and changed from part-time to non-employed. Using the unweighted data, (Model 3 in Table 3 and Figure 3) we found that mothers who worked full-time both before and during the pandemic experienced a 0.27 -unit increase in stress, which was significantly smaller than their peers not raising children (1.13 units). A similar pattern was observed among women who shifted from full-time to part-time/not working following the pandemic onset. In contrast, among women who worked part-time or did not work for pay both before and during the pandemic, as well as those who changed from part-time working to not working during the pandemic, mothers and non-mothers reported similar increases in stress. The weighted model (Model 3 in Appendix C) shows similar results. Further, among women with different mothering and employment statuses, mothers who worked full-time both before and during the pandemic fared relatively better and faced smaller stress increases than women in most other groups (Model 3 in Appendix D). 
[Insert Figure 3 about here]

\section{Discussion}

Using primary data from the second wave of Assessing the Social Consequences of COVID-19 (ASCC) study, we found evidence that the association between women's mothering status and stress increases during early days of the pandemic was conditioned by weekly work hours and employment status. Specifically, among women who worked full-time during the pandemic, mothers experienced smaller increases in stress following pandemic onset compared to nonmothers. Whereas among part-time employed and non-employed women, mothers and nonmothers reported similar increases in stress levels. Full-time working mothers also experienced smaller increases in stress than women with most other mothering and employment statuses. Further, work hour reduction following the pandemic outbreak seemed to have limited impacts on changes in women's stress. Mothers who worked full-time before the pandemic reported smaller stress increases than their peers not raising children, regardless of whether they continued working full-time during the pandemic or not. Among women who worked part-time before the pandemic, mothers reported similar levels of stress increase as non-mothers regardless of stopping work after the pandemic outbreak or not.

Although women generally experienced stress increases during the pandemic, full-time working mothers fared relatively better and faced smaller stress increases, especially when compared with part-time and non-employed mothers, and full-time employed non-mothers. A potential explanation for this finding is that following the closure of schools and day care facilities in response to the pandemic, children have been spending most of their time at home. Children being at home can increase mothers' burden from childcare and homeschooling (Heggeness and 
Fields 2020; Kochhar 2020). Yet, it may also eliminate some of the schedule conflicts between mothers and their children, and reduce the number of activities associated with intensive mothering such as chauffeuring, attending children's extracurricular events, and arranging activities and playdates, all of which can be sources of stress for mothers, particularly full-time working mothers (Gunderson and Barrett 2017; Milkie et al. 2019; Nomaguchi, Milkie, and Bianchi 2005; Rizzo et al. 2013). Further, in the early days of the pandemic, many full-time employed mothers may have experienced a temporary decrease in paid work hours and workloads due to the transition to remote working (Collins et al. 2021; Landivar et al. 2020). Reducing employment workloads to make space for increasing domestic demands and childcare responsibilities during the pandemic may have also become more acceptable in the workplace compared to pre-pandemic times. These may relieve some of the work-family conflicts that full-time employed mothers face, allowing them to engage more with children and perhaps get more sleep and leisure, which are found to be effective in reducing mothers' parental stress (Bianchi 2011; Kelly et al. 2014; Marshall and Tracy 2009; Milkie et al. 2019; Schnittker 2007). During the early days of the pandemic, when these data were collected, the mental health of full-time employed mothers, especially their stress levels might still be benefiting from the temporary reduction of work-family conflicts. The rewards of mothering might also be amplified as mothers spent more meaningful time engaged with their children (Musick et al. 2016; Negraia and Augustine 2020; Offer 2014). We also found it is mainly among women with coresiding spouses/partners that full-time employed mothers experienced smaller stress increases than women in other groups. Among women without coresiding spouses/partners, the stress changes of women with different mothering and employment statuses were similar. However, the triple interaction of mothering status, employment status, and the presence of coresiding spouses/partners was not significant (results not presented). Because only 61 mothers 
reported not having coresiding spouses/partners during the pandemic (18 working full-time, 4 working part-time, and 29 not working), the validity of the results is questionable. Therefore, we cannot rule out the possibility that full-time working mothers experience smaller stress increases than women with other mothering and employment statuses only when having a coresiding spouse/partner to provide childcare, employment, and emotional support. But to what extent this is true requires further analysis.

Compared to mothers employed full-time, similarly employed non-mothers were less likely to reduce their work hours during the pandemic due to domestic responsibilities (Heggeness and Fields 2020; Landivar et al. 2020). Many of them may have even taken extra workloads because of the lay-offs and reduced hours of other workers, and hence experienced more workrelated stress than pre-pandemic. Although potentially facing great stress from work, non-mothers may not receive as much emotional and social support during the pandemic as mothers do. Prior work shows that parenting can strengthen adults' ties with extended family members and neighbors who can provide help in times of difficulty (Gallagher and Gerstel 2001; Kalmijn 2012; Nomaguchi and Milkie 2003). This means that compared with mothers, women not raising children may have fewer people to rely on during the pandemic. Besides, the cancellation of social events and the closure of entertainment venues following the pandemic onset may have also restricted non-mothers' access to friends and leisure activities that they used to rely on for coping with stress pre-pandemic. Therefore, working long hours without the "usual" leisure outlets during the pandemic may have been especially stressful for non-mothers.

Other possible explanations for the small increase in stress among full-time employed mothers during the pandemic include their high pre-pandemic stress levels and stress coping abilities. We found that before the pandemic onset, full-time employed mothers tended to report 
higher levels of stress than non-mothers, and mothers of other employment statuses (see Appendix E). Full-time employed mothers, who during non-pandemic times need to juggle many responsibilities in order to meet the demands of full-time employment and mothering, may be better equipped via their previous experience to deal with the sudden increase of stressors during a crisis like the COVID-19 pandemic. Despite the complex relationship between employment and mothers' mental well-being, existing studies do generally show that maternal employment can provide economic, psychological, and social resources that are beneficial to mothers' emotional well-being (Blair-Loy 2003; Meier et al. 2016; Nomaguchi and Brown 2011; Nomaguchi and Johnson 2016; Nomaguchi and Milkie 2020). Therefore, having more already-established strategies and resources for coping with stress in situations of crisis may also be a reason why fulltime employed mothers' feelings of stress increased less following the onset of the pandemic than most women with other mothering and employment status ${ }^{6}$. This same mechanism may also explain why among women who shifted from working full-time to working part-time or not working after the pandemic outbreak, mothers still experienced smaller stress increases than nonmothers.

Economic difficulties and perceived financial strain may also be one of the reasons why part-time and non-employed mothers experienced greater increases in stress than full-time working mothers during the pandemic. Prior literature shows that employment can benefit women's wellbeing through a variety of mechanisms, one of which is by providing economic security (Frech and Damaske 2012; Marshall and Tracy 2009; Pavalko and Smith 1999; Ross and Mirowsky 1995; Schnittker 2007). Thus, employed women may be less vulnerable to the financial difficulties caused by the pandemic than women who are unemployed or out of the labor force. Similarly, among employed women, those working part-time may have encountered greater financial 
difficulties compared with full-time employed women given that, in the U.S., part-time jobs tend to pay lower wages, provide fewer benefits, and have higher risks of termination than full-time jobs (Frech and Damaske 2012; Kalleberg, Reskin, and Hudson 2000). While we argued above that spending time with children may play a protective role for mothers' mental health in times of crisis, this may only be valid for mothers who have full-time jobs. For part-time and non-employed mothers, the fear of encountering financial difficulties and not being able to provide for children's needs may increase their feelings of stress. However, the level of stress increase that furloughed mothers reported was as low as that of full-time working mothers. This may be because people still expected a fast recovery from the pandemic in April and May 2020. The expectations that jobs and income will return in the near future may make furloughed mothers worry less about longterm financial difficulties and enjoy their time with children at home. The seasonal fluctuation of mothers' employment is also relevant. Before the pandemic, mothers' employment rates decreased between June and September (Heggeness et al. 2021). For mothers who leave their jobs in June and return in September every year, being furloughed in April and May 2020 might not cause financial-related stress if they expected the pandemic to end by September.

The results of this study suggest that during times of crisis such as a pandemic outbreak, full-time employment may protect mothers' mental health, possibly by providing financial security and sufficient childcare resources, offering mothers capabilities to cope with the stress caused by sudden life changes, and giving them meaningful things to do (paid work and spending time with children) to take their mind off the threat of the pandemic. However, full-time employment and long paid working hours did not seem to benefit non-mothers' mental health during the pandemic.

Certain limitations of this study are worth noting. First, the mental health consequences of the COVID-19 pandemic that we observed in this study may only be short-term because the data 
we used were collected during the early months of the pandemic (April 7 and May 15, 2020). For example, the long-term consequences of reduced work hours on mothers' and non-mothers' mental well-being may not have shown up at the early stages of the pandemic when people still hoped for a fast rebound and government financial support. Second, constrained by data limitations and the small sample size of mothers parenting minor children (365), we cannot conduct more detailed analyses to explore, for example, whether the impacts of mothering and employment statuses on stress vary by occupational characteristics, marital status, and living arrangement. Future research should explore these questions systematically. Third, as mentioned above, the retrospective reports of pre-pandemic stress levels are prone to bias. Fourth, the ASCC data is not nationally representative. We weighted the data based on the sociodemographic characteristics of mothers and non-mothers in the nationally representative 2018 GSS data, but remained cautious about the generalizability of the results to the US population.

Despite these limitations, our research makes key contributions to the study of the COVID19 pandemic's impacts on U.S. women's mental health. To our knowledge, the ASCC study is the only available dataset collected during the early days of the pandemic which contains measures of both pre- and during-pandemic stress, parenting, and employment status, and for whom it can be determined if respondents were able to work from home. This study is also among the first to provide empirical evidence that the mental health consequences of the COVID-19 pandemic on American women vary depending on their parenting and employment statuses. Because mothering was associated with smaller stress increases during the pandemic only when combined with fulltime employment, we call for more financial, child care, and emotional support for part-time working and non-employed mothers. Also, as a growing share of women delays or opts out of 
parenting (Lesthaeghe 2010), we call for more family and social support to shelter women not raising children from the negative mental health consequences of the pandemic.

\section{Notes}

1. Wave 1 of the ASCC data was collected prior to the pandemic, but its measure of stress was not comparable to that of the wave 2 . The wave 1 data had 407 respondents, only 213 of them were reinterviewed in the wave 2 (among them, 42 were mothers coresiding with their children).

2. We combined "change from full-time to part-time" and "change from full-time to non-employed" together because the results were similar for these two groups.

3. Occupation is dummy coded as: Management, professional, service, sales, administrative work, farming/fishing, construction, maintenance, production, transportation, others, and not working for pay.

4. Respondents only reported the number of children they have. Information on how many children they coresided with during the pandemic was not available.

5. We found the pre-pandemic stress difference between mothers and non-mothers was conditioned by employment status. Among full-time working women, mothers reported greater stress than non-mothers. Among women with other employment statuses, the stress levels of mothers and non-mothers were similar (see Appendix E).

6. Another possible explanation is that full-time working mothers started out with higher stress than women in other groups before the pandemic, leaving them a smaller room for stress increase during the pandemic. However, full-time employed mothers' during-COVID stress level (5.57) was close to the sample average (5.59) and lower than the upper limit of 10 for the stress measure (Appendix E). Therefore, we believe full-time employed mothers' smaller stress increases during 
the pandemic were unlikely to be caused by not having enough room for stress increases. Their pre-pandemic experience in dealing with stressful events and better coping abilities is a preferable explanation. 


\section{References}

Adams, Elizabeth L., Danyel Smith, Laura J. Caccavale, and Melanie K. Bean. 2021. "Parents Are Stressed! Patterns of Parent Stress Across COVID-19.” Frontiers in Psychiatry 12:626456.

Allison, Paul D. 2001. Missing Data. Thousand Oaks: SAGE Publications.

Alon, Titan, Matthias Doepke, Jane Olmstead-Rumsey, and Michèle Tertilt. 2020. "The Impact of COVID-19 on Gender Equality". National Bureau of Economic Research. Retrieved July 10, 2020 (https://www.nber.org/system/files/working_papers/w26947/w26947.pdf).

American Psychological Association (APA). 2021. "Stress in America Press Room." Retrieved June 13, 2021 (https://www.apa.org/news/press/releases/stress).

Bambra, Clare, Ryan Riordan, John Ford, and Fiona Matthews. 2020. "The COVID-19 Pandemic and Health Inequalities." Journal of Epidemiology and Community Health jech-2020214401.

Bianchi, Suzanne M. 2011. "Changing Families, Changing Workplaces.” The Future of Children 21(2):15-36.

Bianchi, Suzanne M., Melissa A. Milkie, Liana C. Sayer, and John P. Robinson. 2000. "Is Anyone Doing the Housework Trends in the Gender Division of Household Labor." Social Forces 79(1):191-228.

Bianchi, Suzanne M., Liana C. Sayer, Melissa A. Milkie, and John P. Robinson. 2012. "Housework: Who Did, Does or Will Do It, and How Much Does It Matter?" Social Forces 91(1):55-63.

Blair-Loy, Mary. 2003. Competing Devotions: Career and Family among Women Executives. Cambridge, MA: Harvard University Press.

Buehler, Cheryl, and Marion O'Brien. 2011. "Mothers' Part-Time Employment: Associations with Mother and Family Well-Being." Journal of Family Psychology 25(6):895-906.

Caputo, Jennifer, Eliza K. Pavalko, and Melissa A. Hardy. 2020. “Midlife Work and Women's Long-Term Health and Mortality.” Demography 57(1):373-402.

Carrillo, Dani, Kristen Harknett, Allison Logan, Sigrid Luhr, and Daniel Schneider. 2017. "Instability of Work and Care: How Work Schedules Shape Child-Care Arrangements for Parents Working in the Service Sector." Social Service Review 91(3):422-55.

Claxton, Amy, and Maureen Perry-Jenkins. 2008. "No Fun Anymore: Leisure and Marital Quality Across the Transition to Parenthood." Journal of Marriage and Family 70(1):28-43.

Collins, Caitlyn, Liana Christin Landivar, Leah Ruppanner, and William J. Scarborough. 2021. "COVID-19 and the Gender Gap in Work Hours." Gender, Work \& Organization 28(S1):101-12.

Craig, Lyn, and Brendan Churchill. 2018. "Parenting Stress and the Use of Formal and Informal Child Care: Associations for Fathers and Mothers." Journal of Family Issues 39(12):320324. 
Craig, Lyn, Francisco Perales, Sergi Vidal, and Janeen Baxter. 2016. "Domestic Outsourcing, Housework Time, and Subjective Time Pressure: New Insights From Longitudinal Data." Journal of Marriage and Family 78(5):1224-36.

Davis, Kelly D., W. Benjamin Goodman, Amy E. Pirretti, and David M. Almeida. 2008. "Nonstandard Work Schedules, Perceived Family Well-Being, and Daily Stressors." Journal of Marriage and Family 70(4):991-1003.

Dow, Dawn Marie. 2016. "Integrated Motherhood: Beyond Hegemonic Ideologies of Motherhood." Journal of Marriage and Family 78(1):180-96.

Evans, Subhadra, Antonina Mikocka-Walus, Anna Klas, Lisa Olive, Emma Sciberras, Gery Karantzas, and Elizabeth M. Westrupp. 2020. "From 'It Has Stopped Our Lives' to 'Spending More Time Together Has Strengthened Bonds': The Varied Experiences of Australian Families During COVID-19." Frontiers in Psychology 11:588667.

Fitzpatrick, Kevin M., Casey Harris, and Grant Drawve. 2020. "Fear of COVID-19 and the Mental Health Consequences in America." Psychological Trauma: Theory, Research, Practice, and Policy 12(1):17-21.

Frech, Adrianne, and Sarah Damaske. 2012. "The Relationships between Mothers' Work Pathways and Physical and Mental Health." Journal of Health and Social Behavior 53(4):396-412.

Gallagher, Sally K., and Naomi Gerstel. 2001. "Connections and Constraints: The Effects of Children on Caregiving." Journal of Marriage and Family 63(1):265-75.

Gassman-Pines, Anna, Elizabeth Oltmans Ananat, and John Fitz-Henley. 2020. "COVID-19 and Parent-Child Psychological Well-Being." Pediatrics 146(4):e2020007294.

Glass, Jennifer, Robin W. Simon, and Matthew A. Andersson. 2016. "Parenthood and Happiness: Effects of Work-Family Reconciliation Policies in 22 OECD Countries." American Journal of Sociology 122(3):886-929.

Gunderson, Justine, and Anne E. Barrett. 2017. "Emotional Cost of Emotional Support? The Association Between Intensive Mothering and Psychological Well-Being in Midlife." Journal of Family Issues 38(7):992-1009.

Hammen, Constance. 2005. "Stress and Depression." Annual Review of Clinical Psychology 1(1):293-319.

Hansen, Thomas. 2012. "Parenthood and Happiness: A Review of Folk Theories Versus Empirical Evidence." Social Indicators Research 108(1):29-64.

Hays, Sharon. 1996. The Cultural Contradictions of Motherhood. New Haven: Yale University Press.

Heggeness, Misty L., and Jason M. Fields. 2020. "Working Moms Bear Brunt of Home Schooling While Working During COVID-19." United States Census Bureau. Retrieved November 5, 2020 (https://www.census.gov/library/stories/2020/08/parents-juggle-work-and-childcare-during-pandemic.html). 
Heggeness, Misty L., Jason Fields, Yamin A. Trejo, and Anthony Schulzetenberg. 2021.

Tracking Job Losses for Mothers of School-Age Children During a Health Crisis. United States Census Bureau. Retrieved March 26, 2022

(https://www.census.gov/library/stories/2021/03/moms-work-and-the-pandemic.html)

Ingram, Joanne, Greg Maciejewski, and Christopher J. Hand. 2020. "Changes in Diet, Sleep, and Physical Activity Are Associated with Differences in Negative Mood During COVID-19 Lockdown." Frontiers in Psychology 11:588604.

Kalleberg, Arne L., Barbara F. Reskin, and Ken Hudson. 2000. "Bad Jobs in America: Standard and Nonstandard Employment Relations and Job Quality in the United States." American Sociological Review 65(2):256-78.

Kalmijn, Matthijs. 2012. "Longitudinal Analyses of the Effects of Age, Marriage, and Parenthood on Social Contacts and Support." Advances in Life Course Research 17(4):177-90.

Kelly, Erin L., Phyllis Moen, J. Michael Oakes, Wen Fan, Cassandra Okechukwu, Kelly D. Davis, Leslie B. Hammer, Ellen Ernst Kossek, Rosalind Berkowitz King, Ginger C. Hanson, Frank Mierzwa, and Lynne M. Casper. 2014. "Changing Work and Work-Family Conflict: Evidence from the Work, Family, and Health Network." American Sociological Review 79(3):485-516.

Kochhar, Rakesh. 2020. "Fewer Mothers and Fathers in U.S. Are Working Due to COVID-19 Downturn; Those at Work Have Cut Hours." Pew Research Center. Retrieved January 2, 2021 (https://www.pewresearch.org/fact-tank/2020/10/22/fewer-mothers-and-fathers-inu-s-are-working-due-to-covid-19-downturn-those-at-work-have-cut-hours/).

Kolenikov, Stanislav. 2014. "Calibrating Survey Data Using Iterative Proportional Fitting (Raking)." The Stata Journal: Promoting Communications on Statistics and Stata 14(1):22-59.

Landivar, Liana Christin, Leah Ruppanner, William J. Scarborough, and Caitlyn Collins. 2020. "Early Signs Indicate That COVID-19 Is Exacerbating Gender Inequality in the Labor Force." Socius: Sociological Research for a Dynamic World 6:1-3.

Lareau, Annette. 2011. Unequal Childhoods: Class, Race, and Family Life. Second. Berkeley: University of California Press.

Laster Pirtle, Whitney N., and Tashelle Wright. 2021. "Structural Gendered Racism Revealed in Pandemic Times: Intersectional Approaches to Understanding Race and Gender Health Inequities in COVID-19." Gender \& Society 35(2):168-79.

Lesthaeghe, Ron. 2010. "The Unfolding Story of the Second Demographic Transition." Population and Development Review 36(2):211-51.

Manville, Michael, Paavo Monkkonen, Michael Lens, and Richard Green. 2020. COVID-19 and Renter Distress: Evidence from Los Angeles. Los Angeles: UCLA.

Margolis, Rachel, and Mikko Myrskylä. 2011. "A Global Perspective on Happiness and Fertility." Population and Development Review 37(1):29-56.

Marshall, Nancy L., and Allison J. Tracy. 2009. "After the Baby: Work-Family Conflict and Working Mothers' Psychological Health.” Family Relations 58(4):380-91. 
McGinty, Emma E., Rachel Presskreischer, Hahrie Han, and Colleen L. Barry. 2020. "Psychological Distress and Loneliness Reported by US Adults in 2018 and April 2020." JAMA 324(1):93.

McLanahan, Sara, and Julia Adams. 1987. "Parenthood and Psychological Well-Being." Annual Review of Sociology 13(1):237-57.

Meier, Ann, Kelly Musick, Sarah Flood, and Rachel Dunifon. 2016. "Mothering Experiences: How Single Parenthood and Employment Structure the Emotional Valence of Parenting." Demography 53(3):649-74.

Melchior, Maria, Avshalom Caspi, Barry J. Milne, Andrea Danese, Richie Poulton, and Terrie E. Moffitt. 2007. "Work Stress Precipitates Depression and Anxiety in Young, Working Women and Men." Psychological Medicine 37(8):1119-29.

Milkie, Melissa A., Kei Nomaguchi, and Scott Schieman. 2019. "Time Deficits with Children: The Link to Parents' Mental and Physical Health." Society and Mental Health 9(3):277-95.

Mill, Aire, Anu Realo, and Jüri Allik. 2016. "Retrospective Ratings of Emotions: The Effects of Age, Daily Tiredness, and Personality." Frontiers in Psychology 6. doi: 10.3389/fpsyg.2015.02020.

Moen, Phyllis, and Patricia V. Roehling. 2005. The Career Mystique: Cracks in the American Dream. Lanham: Rowman \& Littlefield.

Musick, Kelly, Ann Meier, and Sarah Flood. 2016. "How Parents Fare: Mothers' and Fathers' Subjective Well-Being in Time with Children." American Sociological Review 81(5):1069-95.

Negraia, Daniela V., Jill E. Yavorsky, and Denys Dukhovnov. 2020. “Mothers' and Fathers' WellBeing: Does the Gender Composition of Children Matter?" Journal of Marriage and Family 83(3):820-844

Negraia, Daniela Veronica, and Jennifer March Augustine. 2020. "Unpacking the Parenting WellBeing Gap: The Role of Dynamic Features of Daily Life across Broader Social Contexts." Social Psychology Quarterly 83(3):207-28.

Negraia, Daniela Veronica, Jennifer March Augustine, and Kate Chambers Prickett. 2018. "Gender Disparities in Parenting Time Across Activities, Child Ages, and Educational Groups.” Journal of Family Issues 39(11):3006-28.

Nelson, S. Katherine, Kostadin Kushlev, Tammy English, Elizabeth W. Dunn, and Sonja Lyubomirsky. 2013. "In Defense of Parenthood: Children Are Associated with More Joy Than Misery." Psychological Science 24(1):3-10.

Nelson, S. Katherine, Kostadin Kushlev, and Sonja Lyubomirsky. 2014. "The Pains and Pleasures of Parenting: When, Why, and How Is Parenthood Associated with More or Less WellBeing?" Psychological Bulletin 140(3):846-95.

Nomaguchi, Kei, and Susan L. Brown. 2011. "Parental Strains and Rewards Among Mothers: The Role of Education.” Journal of Marriage and Family 73(3):621-36.

Nomaguchi, Kei, and Wendi Johnson. 2016. "Parenting Stress Among Low-Income and WorkingClass Fathers: The Role of Employment.” Journal of Family Issues 37(11):1535-57. 
Nomaguchi, Kei, and Melissa A. Milkie. 2003. "Costs and Rewards of Children: The Effects of Becoming a Parent on Adults' Lives.” Journal of Marriage and Family 65(2):356-74.

Nomaguchi, Kei, and Melissa A. Milkie. 2017. "Sociological Perspectives on Parenting Stress: How Social Structure and Culture Shape Parental Strain and the Well-Being of Parents and Children." Pp. 47-73 in Parental Stress and Early Child Development, edited by K. DeaterDeckard and R. Panneton. New York: Springer.

Nomaguchi, Kei, and Melissa A. Milkie. 2020. "Parenthood and Well-Being: A Decade in Review." Journal of Marriage and Family 82(1):198-223.

Nomaguchi, Kei, Melissa A. Milkie, and Suzanne M. Bianchi. 2005. "Time Strains and Psychological Well-Being: Do Dual-Earner Mothers and Fathers Differ?" Journal of Family Issues 26(6):756-92.

Offer, Shira. 2014. “Time with Children and Employed Parents' Emotional Well-Being.” Social Science Research 47:192-203.

Parker, Kim, Juliana Menasce Horowitz, and Rachel Minkin. 2020. How the Coronavirus Outbreak Has - and Hasn't - Changed the Way Americans Work. Pew Research Center.

Pavalko, Eliza K. 1999. "The Rhythm of Work: Health Effects of Women's Work Dynamics." Social Forces 77(3):1141-62.

Pearlin, Leonard I. 1999. "Stress and Mental Health: A Conceptual Overview." Pp. 161-75 in $A$ handbook for the study of mental health: Social contexts, theories, and systems, edited by A. V. Horwitz and T. L. Scheid. Cambridge: Cambridge University Press.

Pew Research Center. 2020a. "About Half of Lower Income Americans Report Household Wage or Job Loss Due to COVID-19." Retrieved July 15, 2020

(https://www.pewsocialtrends.org/2020/04/21/about-half-of-lower-income-americansreport-household-job-or-wage-loss-due-to-covid-19/).

Pew Research Center. 2020b. "Most Americans Say Coronavirus Outbreak Has Impacted Their Lives." Retrieved July 15, 2020 (https://www.pewsocialtrends.org/2020/03/30/mostamericans-say-coronavirus-outbreak-has-impacted-their-lives/).

Pollmann-Schult, Matthias. 2014. "Parenthood and Life Satisfaction: Why Don't Children Make People Happy? Parenthood and Life Satisfaction." Journal of Marriage and Family 76(2):319-36.

Rizzo, Kathryn M., Holly H. Schiffrin, and Miriam Liss. 2013. "Insight into the Parenthood Paradox: Mental Health Outcomes of Intensive Mothering." Journal of Child and Family Studies 22(5):614-20.

Ross, Catherine E., and John Mirowsky. 1995. "Does Employment Affect Health?” Journal of Health and Social Behavior 36(3):230-43.

Roxburgh, Susan. 2012. "Parental Time Pressures and Depression Among Married Dual-Earner Parents." Journal of Family Issues 33(8):1027-53.

Salari, Nader, Amin Hosseinian-Far, Rostam Jalali, Aliakbar Vaisi-Raygani, Shna Rasoulpoor, Masoud Mohammadi, Shabnam Rasoulpoor, and Behnam Khaledi-Paveh. 2020. "Prevalence of Stress, Anxiety, Depression among the General Population during the 
COVID-19 Pandemic: A Systematic Review and Meta-Analysis." Globalization and Health 16(1):57.

Sayer, Liana C. 2016. “Trends in Women's and Men's Time Use, 1965-2012: Back to the Future?" Pp. 43-77 in Gender and Couple Relationships. National Symposium on Family Issues. Vol. 6, edited by S. M. McHale, V. King, Jennifer. Van Hook, and A. Booth. Springer, Charm.

Schnittker, Jason. 2007. "Working More and Feeling Better: Women's Health, Employment, and Family Life, 1974-2004.” American Sociological Review 72(2):221-38.

Stockman, Jamila K., Brittany A. Wood, and Katherine M. Anderson. 2021. "Racial and Ethnic Differences in COVID-19 Outcomes, Stressors, Fear, and Prevention Behaviors Among US Women: Web-Based Cross-Sectional Study." Journal of Medical Internet Research 23(7):e26296.

Turner, Heather A., and R. Jay Turner. 2005. "Understanding Variations in Exposure to Social Stress." Health: An Interdisciplinary Journal for the Social Study of Health, Illness and Medicine 9(2):209-40.

Turner, R. Jay, Blair Wheaton, and Donald A. Lloyd. 1995. "The Epidemiology of Social Stress.” American Sociological Review 60(1):104-25.

Uehara, Misato, Makoto Fujii, and Kazuki Kobayashi. 2021. "A Model of Stress Change under the First COVID-19 Pandemic among the General Public in Japanese Major Cities and Rural Areas." Sustainability 13(3):1207. doi: 10.3390/su13031207.

Umberson, Debra, Tetyana Pudrovska, and Corinne Reczek. 2010. "Parenthood, Childlessness, and Well-Being: A Life Course Perspective.” Journal of Marriage and Family 72(3):61229.

Wheaton, Blair, and Shirin Montazer. 2009. "Stressors, Stress, and Distress." Pp. 171-99 in $A$ Handbook for the Study of Mental Health: Social Contexts, Theories, and Systems, edited by T. L. Scheid and T. N. Brown. Cambridge: Cambridge University Press. 
Table 1. Descriptive Characteristics (Means and Percentages) of Sampled Women by Mothering Status $(\mathrm{N}=1,505)$.

\begin{tabular}{|c|c|c|c|c|}
\hline & \multicolumn{2}{|c|}{ Unweighted } & \multicolumn{2}{|c|}{ Weighted } \\
\hline & Non-mothers & Mothers & Non-mothers & Mothers \\
\hline Pre-COVID stress & $\begin{array}{c}5.78 \\
(2.13)\end{array}$ & $\begin{array}{c}4.42 \\
(232)\end{array}$ & $\begin{array}{c}4.60 \\
(247)\end{array}$ & $\begin{array}{c}4.50 \\
(178)\end{array}$ \\
\hline During-COVID stress & $\begin{array}{c}5.68 \\
(2.32)\end{array}$ & $\begin{array}{c}5.33 \\
(2.58)\end{array}$ & $\begin{array}{c}5.62 \\
(2.88)\end{array}$ & $\begin{array}{c}5.45 \\
(1.95)\end{array}$ \\
\hline Stress change & $\begin{array}{c}0.90 \\
(2.27)\end{array}$ & $\begin{array}{c}0.91 \\
(2.51)\end{array}$ & $\begin{array}{c}1.02 \\
(2.51)\end{array}$ & $\begin{array}{c}0.95 \\
(1.86)\end{array}$ \\
\hline During-COVID weekly work hours (\%) & & & & \\
\hline $\begin{array}{l}35 \text { or more } \\
1-34 \\
0\end{array}$ & $\begin{array}{l}29.0 \\
26.8 \\
44.1\end{array}$ & $\begin{array}{l}30.4 \\
25.8 \\
43.8\end{array}$ & $\begin{array}{l}30.8 \\
17.9 \\
51.3\end{array}$ & $\begin{array}{l}25.9 \\
21.6 \\
52.5\end{array}$ \\
\hline During-COVID employment status (\%) & & & & \\
\hline $\begin{array}{l}\text { Full-time } \\
\text { Part-time } \\
\text { Self-employed } \\
\text { Furloughed } \\
\text { Unemployed/Not in the labor force }\end{array}$ & $\begin{array}{c}29.0 \\
15.4 \\
9.4 \\
9.7 \\
34.2\end{array}$ & $\begin{array}{c}32.6 \\
16.2 \\
8.2 \\
6.0 \\
37.0\end{array}$ & $\begin{array}{c}30.8 \\
10.4 \\
7.7 \\
9.6 \\
41.6\end{array}$ & $\begin{array}{c}25.9 \\
14.3 \\
7.8 \\
5.6 \\
46.5\end{array}$ \\
\hline Employment status change (\%) & & & & \\
\hline $\begin{array}{l}\text { Always full-time } \\
\text { Always part-time } \\
\text { Always non-employed } \\
\text { From full-time to part-time/non-employed } \\
\text { From part-time to non-employed } \\
\text { Part-time/non-employed to full-time or non- } \\
\text { employed to part-time }\end{array}$ & $\begin{array}{l}27.3 \\
15.9 \\
17.6 \\
21.1 \\
15.8 \\
2.3\end{array}$ & $\begin{array}{c}29.3 \\
14.0 \\
17.3 \\
25.2 \\
12.9 \\
1.4\end{array}$ & $\begin{array}{c}30.2 \\
8.2 \\
32.2 \\
22.6 \\
6.2 \\
0.7\end{array}$ & $\begin{array}{c}24.5 \\
11.7 \\
29.0 \\
22.8 \\
10.2 \\
1.9\end{array}$ \\
\hline Age & $\begin{array}{l}28.06 \\
(7.50)\end{array}$ & $\begin{array}{l}34.86 \\
(6.49)\end{array}$ & $\begin{array}{l}32.39 \\
(9.88)\end{array}$ & $\begin{array}{l}35.88 \\
(5.46)\end{array}$ \\
\hline Race (\%) & & & & \\
\hline White & 60.4 & 73.2 & 63.2 & 69.5 \\
\hline Hispanic & 6.8 & 6.6 & 2.7 & 6.6 \\
\hline Black & 8.5 & 5.8 & 21.1 & 13.1 \\
\hline Asian & 12.6 & 4.7 & 5.5 & 2.7 \\
\hline Others & 11.8 & 9.9 & 7.6 & 8.2 \\
\hline Yeas of education & $\begin{array}{l}15.03 \\
(2.17)\end{array}$ & $\begin{array}{l}15.10 \\
(2.13)\end{array}$ & $\begin{array}{l}14.30 \\
(2.32)\end{array}$ & $\begin{array}{l}14.30 \\
(1.51)\end{array}$ \\
\hline Pre-COVID employment status (\%) & & & & \\
\hline Full-time & 42.9 & 46.0 & 44.6 & 38.0 \\
\hline Part-time & 23.7 & 14.3 & 11.0 & 12.9 \\
\hline Self-employed & 10.4 & 10.7 & 8.8 & 9.5 \\
\hline Furloughed & 1.1 & 0 & 2.9 & 0 \\
\hline Unemployed/Not in the labor force & 22.0 & 29.0 & 32.7 & 39.7 \\
\hline Household income (\%) & & & & \\
\hline Lower than $20 \mathrm{k}$ & 16.1 & 11.2 & 16.7 & 15.3 \\
\hline $20 \mathrm{k}-60 \mathrm{k}$ & 38.3 & 35.3 & 37.9 & 38.3 \\
\hline $60 \mathrm{k}-100 \mathrm{k}$ & 23.7 & 33.4 & 25.4 & 25.0 \\
\hline Higher than $100 \mathrm{k}$ & 22.0 & 20.0 & 20.0 & 21.5 \\
\hline Household income change (\%) & & & & \\
\hline Decreased & 46.5 & 45.5 & 48.4 & 41.9 \\
\hline Stayed the same & 45.9 & 48 & 43 & 53 \\
\hline Increased & 7.6 & 6.6 & 8.7 & 5.1 \\
\hline
\end{tabular}




\begin{tabular}{lcccc}
\hline Home ownership (\%) & & & \\
$\quad$ Own with mortgage & 33.3 & 58.1 & 35.1 & 54.9 \\
Own in full & 11.3 & 9.3 & 11.5 & 7.8 \\
Rent/Occupied & 55.4 & 32.6 & 53.4 & 37.4 \\
Spent 80\% or more paid work time at home (\%) & & & & \\
No & 6.1 & 4.7 & 6.4 & 6.6 \\
Yes & 21.1 & 20.0 & 18.0 & 16.2 \\
Not employed/no information & 72.9 & 75.3 & 75.6 & 77.2 \\
Married during-COVID (\%) & 18.3 & 68.0 & 40.7 & 58.9 \\
Live with spouse/partner during-COVID (\%) & 38.7 & 83.3 & 54.4 & 78.0 \\
Live with parents/siblings during-COVID (\%) & 34.0 & 10.4 & 32.8 & 13.4 \\
Live with roommates/friends/others during-COVID (\%) & 23.1 & 8.0 & 13.7 & 8.7 \\
Number of children aged 0-6 & 0.02 & 0.83 & 0.07 & 0.77 \\
$\quad$ & $(0.18)$ & $(0.80)$ & $(0.39)$ & $(0.61)$ \\
Number of children aged 7-12 & 0.02 & 0.75 & 0.03 & 0.75 \\
$\quad$ & $(0.16)$ & $(0.86)$ & $(0.23)$ & $(0.67)$ \\
Number of children aged 13-17 & 0.01 & 0.32 & 0.01 & 0.37 \\
$\quad$ & $(0.09)$ & $(0.63)$ & $(0.13)$ & $(0.52)$ \\
Spouse/partner's employment status during-COVID (\%) & & & & \\
$\quad$ Full-time & 37.7 & 70.1 & 39.9 & 61.3 \\
Part-time & 8.4 & 5.2 & 6.9 & 5.2 \\
Self-employed & 3.4 & 5.2 & 3.8 & 4.0 \\
Furloughed & 0.5 & 0.6 & 7.1 & 5.3 \\
Unemployed/Not in the labor force & 9.4 & 6.3 & 8.4 & 7.1 \\
No spouse/partner & 40.5 & 12.6 & 33.9 & 17.1 \\
N & 1,140 & 365 & 1,140 & 365 \\
\hline
\end{tabular}

Note: Standard deviations in parenthesis. 
Table 2. Predicted Stress Levels Before and During the COVID-19, and the Change of Stress Levels After the COVID-19 Outbreak by Mothering Status ( $N=1,505$, unweighted).

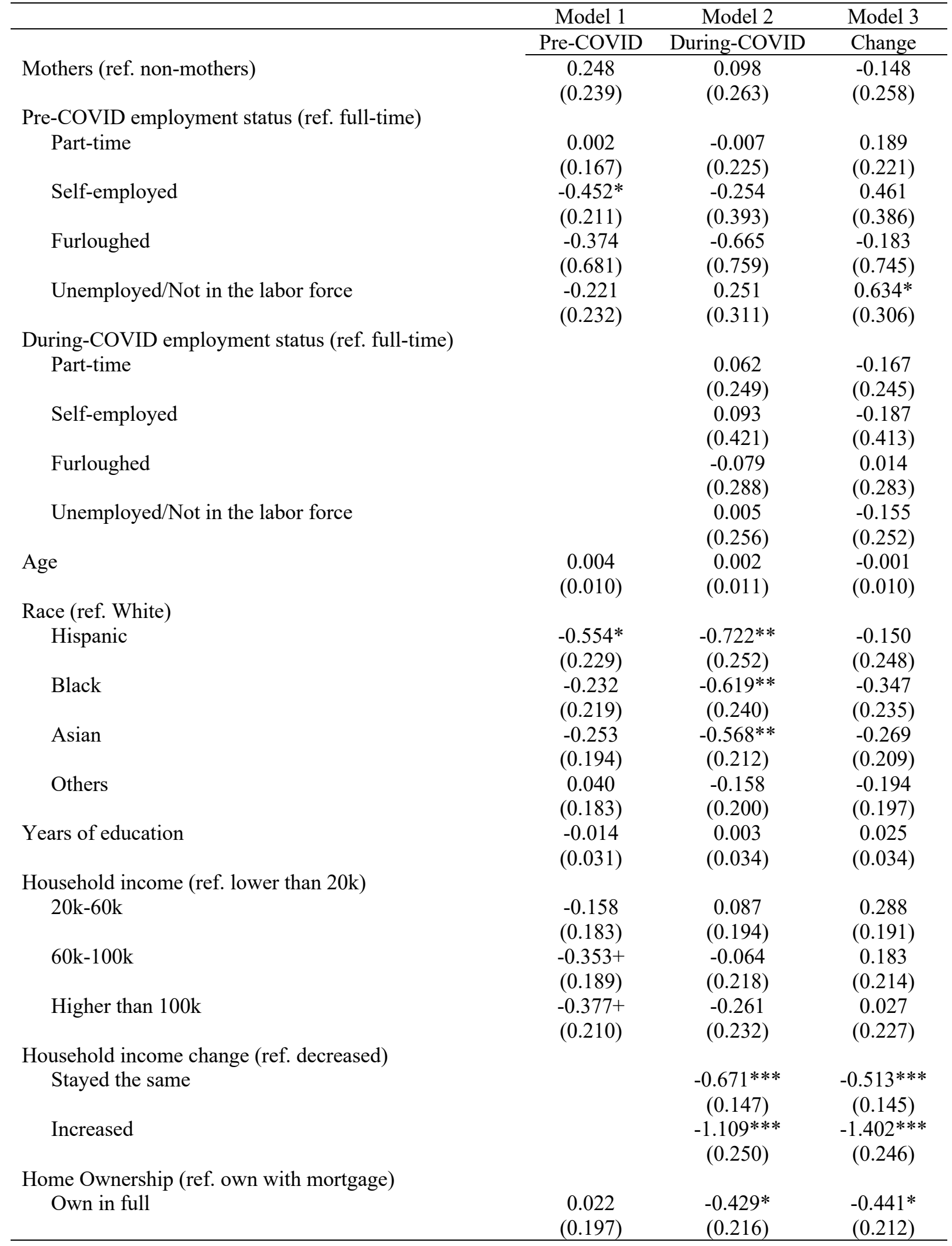




\begin{tabular}{|c|c|c|c|}
\hline Rented or occupied & $\begin{array}{c}0.203 \\
(0.138)\end{array}$ & $\begin{array}{c}0.055 \\
(0.151)\end{array}$ & $\begin{array}{l}-0.200 \\
(0.148)\end{array}$ \\
\hline \multicolumn{4}{|l|}{ Spent $80 \%$ or more paid work time at home (ref. no) } \\
\hline Yes & & $\begin{array}{c}0.248 \\
(0.297)\end{array}$ & $\begin{array}{l}-0.073 \\
(0.292)\end{array}$ \\
\hline Information not available/not employed & & $\begin{array}{c}0.121 \\
(0.284)\end{array}$ & $\begin{array}{l}-0.262 \\
(0.279)\end{array}$ \\
\hline Married pre-COVID (ref. not married) & $\begin{array}{c}-0.470^{*} \\
(0.184)\end{array}$ & & \\
\hline Married during-COVID (ref. not married) & & $\begin{array}{l}-0.022 \\
(0.202)\end{array}$ & $\begin{array}{c}0.305 \\
(0.198)\end{array}$ \\
\hline Live with spouse/partner pre-COVID (ref. no) & $\begin{array}{c}0.656^{* *} \\
(0.199)\end{array}$ & & \\
\hline Live with spouse/partner during-COVID (ref. no) & & $\begin{array}{l}-0.170 \\
(0.225)\end{array}$ & $\begin{array}{c}-0.610^{* *} \\
(0.221)\end{array}$ \\
\hline Live with parents/siblings pre-COVID (ref. no) & $\begin{array}{c}0.510 * * \\
(0.171)\end{array}$ & & \\
\hline Live with parents/siblings during-COVID (ref. no) & & $\begin{array}{c}0.158 \\
(0.185)\end{array}$ & $\begin{array}{l}-0.320+ \\
(0.182)\end{array}$ \\
\hline Live with roommates/friends/others pre-COVID (ref. no) & $\begin{array}{l}0.377^{*} \\
(0.159)\end{array}$ & & \\
\hline Live with roommates/friends/others during-COVID (ref. no) & & $\begin{array}{c}0.285 \\
(0.182)\end{array}$ & $\begin{array}{l}-0.017 \\
(0.179)\end{array}$ \\
\hline Number of children aged $0-6$ & $\begin{array}{c}-0.243+ \\
(0.146)\end{array}$ & $\begin{array}{l}-0.227 \\
(0.161)\end{array}$ & $\begin{array}{c}0.034 \\
(0.158)\end{array}$ \\
\hline Number of children aged 7-12 & $\begin{array}{c}-0.079 \\
(0.132)\end{array}$ & $\begin{array}{l}-0.073 \\
(0.145)\end{array}$ & $\begin{array}{c}0.006 \\
(0.143)\end{array}$ \\
\hline Number of children aged 13-17 & $\begin{array}{c}-0.311+ \\
(0.189)\end{array}$ & $\begin{array}{l}-0.309 \\
(0.207)\end{array}$ & $\begin{array}{l}-0.011 \\
(0.204)\end{array}$ \\
\hline Constant & $\begin{array}{c}5.768 * * * \\
(0.673)\end{array}$ & $\begin{array}{c}6.715 * * * \\
(0.787)\end{array}$ & $\begin{array}{c}1.036 \\
(0.773)\end{array}$ \\
\hline R-squared & 0.057 & 0.063 & 0.051 \\
\hline
\end{tabular}

Note: Results present regression coefficients from OLS models. Standard errors in parentheses. Each model also controlled for occupation and spouse/partners' employment status, but we omit the coefficients to conserve space. ${ }^{*} \mathrm{p}<.05,{ }^{* *} \mathrm{p}<.01,{ }^{* * *} \mathrm{p}<.001,+\mathrm{p}<.10$. 
Table 3. Predicted Stress Level Changes Following the COVID-19 Outbreak by Mothering Status and Employment Status ( $N=1,505$, unweighted).

\begin{tabular}{|c|c|c|c|}
\hline & Model 1 & Model 2 & Model 3 \\
\hline Mothers (ref. non-mothers) & $\begin{array}{l}-0.816^{*} \\
(0.330)\end{array}$ & $\begin{array}{c}-0.757 * \\
(0.322)\end{array}$ & $\begin{array}{c}-0.857^{*} \\
(0.334)\end{array}$ \\
\hline \multicolumn{4}{|l|}{ Weekly work hours (ref. 35-40) } \\
\hline $1-34$ & $\begin{array}{c}-0.303 \\
(0.196)\end{array}$ & & \\
\hline 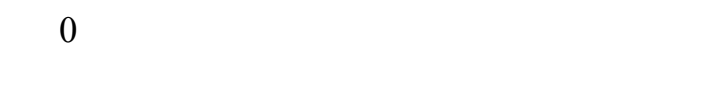 & $\begin{array}{l}-0.211 \\
(0.216)\end{array}$ & & \\
\hline \multicolumn{4}{|l|}{ Mothers*Weekly work hours } \\
\hline Mother*1-34 & $\begin{array}{l}0.963^{*} \\
(0.380)\end{array}$ & & \\
\hline Mother*0 & $\begin{array}{c}0.987 * * \\
(0.345)\end{array}$ & & \\
\hline \multicolumn{4}{|l|}{ Employment status (ref. full-time) } \\
\hline Part-time & & $\begin{array}{l}-0.343 \\
(0.232)\end{array}$ & \\
\hline Self-employed & & $\begin{array}{l}-0.079 \\
(0.279)\end{array}$ & \\
\hline Furloughed & & $\begin{array}{c}0.000 \\
(0.291)\end{array}$ & \\
\hline Unemployed/Not in the labor force & & $\begin{array}{l}-0.175 \\
(0.231)\end{array}$ & \\
\hline \multicolumn{4}{|l|}{ Mothers*Employment status } \\
\hline Mother*Part-time & & $\begin{array}{l}0.985^{*} \\
(0.433)\end{array}$ & \\
\hline Mother*Self-employed & & $\begin{array}{l}1.013+ \\
(0.552)\end{array}$ & \\
\hline Mother*Furloughed & & $\begin{array}{c}0.044 \\
(0.603)\end{array}$ & \\
\hline Mother* Unemployed/Not in the labor force & & $\begin{array}{l}1.090 * * \\
(0.351)\end{array}$ & \\
\hline \multicolumn{4}{|l|}{ Employment change (ref. always full-time) } \\
\hline Always part-time & & & $\begin{array}{l}-0.450+ \\
(0.236)\end{array}$ \\
\hline Always non-employed & & & $\begin{array}{l}-0.101 \\
(0.348)\end{array}$ \\
\hline Full-time to part-time/non-employed & & & $\begin{array}{l}-0.291 \\
(0.216)\end{array}$ \\
\hline Part-time to non-employed & & & $\begin{array}{l}-0.279 \\
(0.261)\end{array}$ \\
\hline \multicolumn{4}{|l|}{ Mothers*Employment change } \\
\hline Mother*Always Part-time & & & $\begin{array}{c}1.214 * * \\
(0.461)\end{array}$ \\
\hline Mother*Always Non-employed & & & $\begin{array}{l}1.364 * * \\
(0.441)\end{array}$ \\
\hline Mother*Full-time to part-time/non-employed & & & $\begin{array}{c}0.611 \\
(0.391)\end{array}$ \\
\hline Mother*Part-time to non-employed & & & $\begin{array}{l}1.383 * * \\
(0.477)\end{array}$ \\
\hline Age & $\begin{array}{l}-0.000 \\
(0.010)\end{array}$ & $\begin{array}{l}-0.000 \\
(0.010)\end{array}$ & $\begin{array}{l}-0.001 \\
(0.010)\end{array}$ \\
\hline
\end{tabular}




\begin{tabular}{|c|c|c|c|}
\hline \multicolumn{4}{|l|}{ Race (ref. White) } \\
\hline \multirow[t]{2}{*}{ Hispanic } & -0.163 & -0.162 & -0.148 \\
\hline & $(0.247)$ & $(0.247)$ & $(0.247)$ \\
\hline \multirow[t]{2}{*}{ Black } & -0.290 & -0.318 & -0.254 \\
\hline & $(0.234)$ & $(0.234)$ & $(0.235)$ \\
\hline \multirow[t]{2}{*}{ Asian } & -0.261 & -0.268 & -0.247 \\
\hline & $(0.208)$ & $(0.208)$ & $(0.209)$ \\
\hline \multirow[t]{2}{*}{ Others } & -0.154 & -0.167 & -0.152 \\
\hline & $(0.197)$ & $(0.197)$ & $(0.196)$ \\
\hline \multirow[t]{2}{*}{ Years of education } & 0.009 & 0.012 & 0.009 \\
\hline & $(0.033)$ & $(0.033)$ & $(0.033)$ \\
\hline \multicolumn{4}{|l|}{ Household income (ref. lower than 20k) } \\
\hline \multirow[t]{2}{*}{ 20k-60k } & 0.208 & 0.203 & 0.193 \\
\hline & $(0.189)$ & $(0.190)$ & $(0.190)$ \\
\hline \multirow[t]{2}{*}{$60 \mathrm{k}-100 \mathrm{k}$} & 0.133 & 0.117 & 0.128 \\
\hline & $(0.213)$ & $(0.214)$ & $(0.213)$ \\
\hline \multirow[t]{2}{*}{ Higher than $100 \mathrm{k}$} & -0.043 & -0.054 & -0.040 \\
\hline & $(0.226)$ & $(0.228)$ & $(0.227)$ \\
\hline \multicolumn{4}{|l|}{ Household income change (ref. decreased) } \\
\hline \multirow[t]{2}{*}{ Stayed the same } & $-0.471 * * *$ & $-0.478 * * *$ & $-0.494 * * *$ \\
\hline & $(0.138)$ & $(0.141)$ & $(0.140)$ \\
\hline \multirow[t]{2}{*}{ Increased } & $-1.373 * * *$ & $-1.353 * * *$ & $-1.354 * * *$ \\
\hline & $(0.243)$ & $(0.244)$ & $(0.246)$ \\
\hline \multicolumn{4}{|l|}{ Home Ownership (ref. own with mortgage) } \\
\hline \multirow[t]{2}{*}{ Own in full } & $-0.399+$ & $-0.418^{*}$ & $-0.382+$ \\
\hline & $(0.211)$ & $(0.212)$ & $(0.211)$ \\
\hline \multirow[t]{2}{*}{ Rented or occupied } & -0.235 & -0.225 & -0.230 \\
\hline & $(0.148)$ & $(0.149)$ & $(0.149)$ \\
\hline \multicolumn{4}{|l|}{ Spent $80 \%$ or more paid work time at home (ref. no) } \\
\hline \multirow[t]{2}{*}{ Yes } & 0.020 & -0.025 & 0.004 \\
\hline & $(0.289)$ & $(0.292)$ & $(0.289)$ \\
\hline \multirow[t]{2}{*}{ Information not available/not employed } & -0.164 & -0.212 & -0.192 \\
\hline & $(0.279)$ & $(0.279)$ & $(0.275)$ \\
\hline \multirow[t]{2}{*}{ Married during-COVID (ref. not married) } & $0.375+$ & $0.389^{*}$ & $0.370+$ \\
\hline & $(0.197)$ & $(0.198)$ & $(0.199)$ \\
\hline \multirow[t]{2}{*}{ Live with spouse/partner during-COVID (ref. no) } & $-0.548 *$ & $-0.562 *$ & $-0.547^{*}$ \\
\hline & $(0.222)$ & $(0.222)$ & $(0.223)$ \\
\hline \multirow[t]{2}{*}{ Live with parents/siblings during-COVID (ref. no) } & -0.273 & -0.248 & -0.277 \\
\hline & $(0.182)$ & $(0.183)$ & $(0.183)$ \\
\hline Live with roommates/friends/others during- & 0.018 & 0.003 & 0.024 \\
\hline COVID (ref. no) & $(0.179)$ & $(0.179)$ & $(0.179)$ \\
\hline Number of children aged $0-6$ & 0.031 & 0.024 & -0.003 \\
\hline & $(0.158)$ & $(0.158)$ & $(0.159)$ \\
\hline Number of children aged 7-12 & -0.004 & 0.017 & -0.006 \\
\hline & $(0.143)$ & $(0.143)$ & $(0.143)$ \\
\hline Number of children aged 13-17 & 0.051 & 0.014 & 0.038 \\
\hline & $(0.205)$ & $(0.207)$ & $(0.206)$ \\
\hline Constant & $1.626^{*}$ & $1.546^{*}$ & $1.524+$ \\
\hline & $(0.736)$ & $(0.744)$ & $(0.796)$ \\
\hline R-squared & 0.056 & 0.059 & 0.062 \\
\hline
\end{tabular}

Note: Results present regression coefficients from OLS models. Standard errors in parentheses. Each model also controlled for occupation and spouse/partner's employment status, but we omit the coefficient to conserve space. $* \mathrm{p}<.05, * * \mathrm{p}<.01, * * * \mathrm{p}<.001,+\mathrm{p}<.10$ 
Figure 1. Predicted Means of Stress Level Changes After the COVID-19 Outbreak by Women's Mothering Status and Work Hours During the COVID-19 ( $N=1,505$, unweighted).

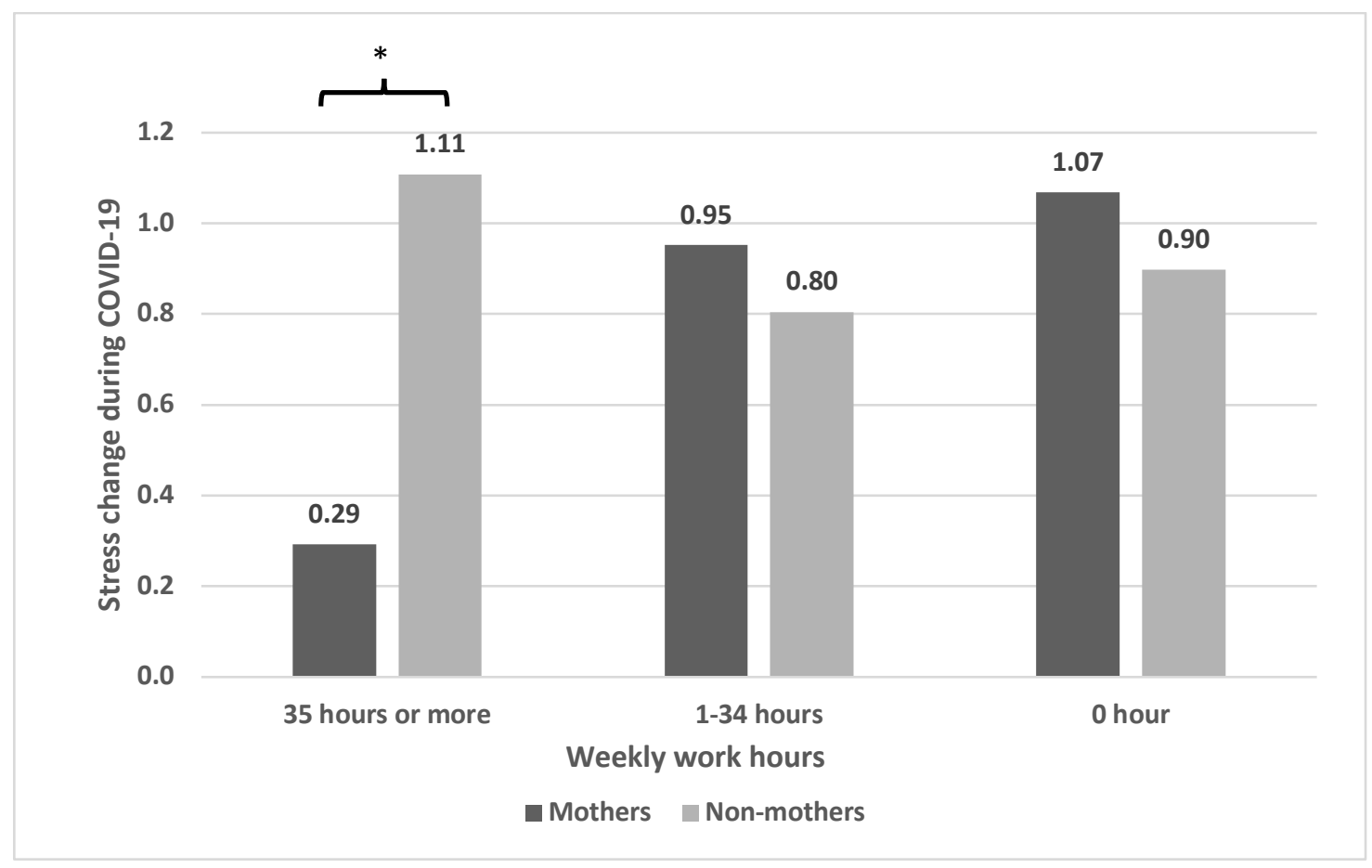

Note: Results present predicted probabilities from OLS models (Model 1 in Table 3).

$* \mathrm{p}<.05, * * \mathrm{p}<.01, * * * \mathrm{p}<.001$. 
Figure 2. Predicted Means of Stress Level Changes After the COVID-19 Outbreak by Women's Mothering Status and Employment Status During the COVID-19 (N=1,505, unweighted)

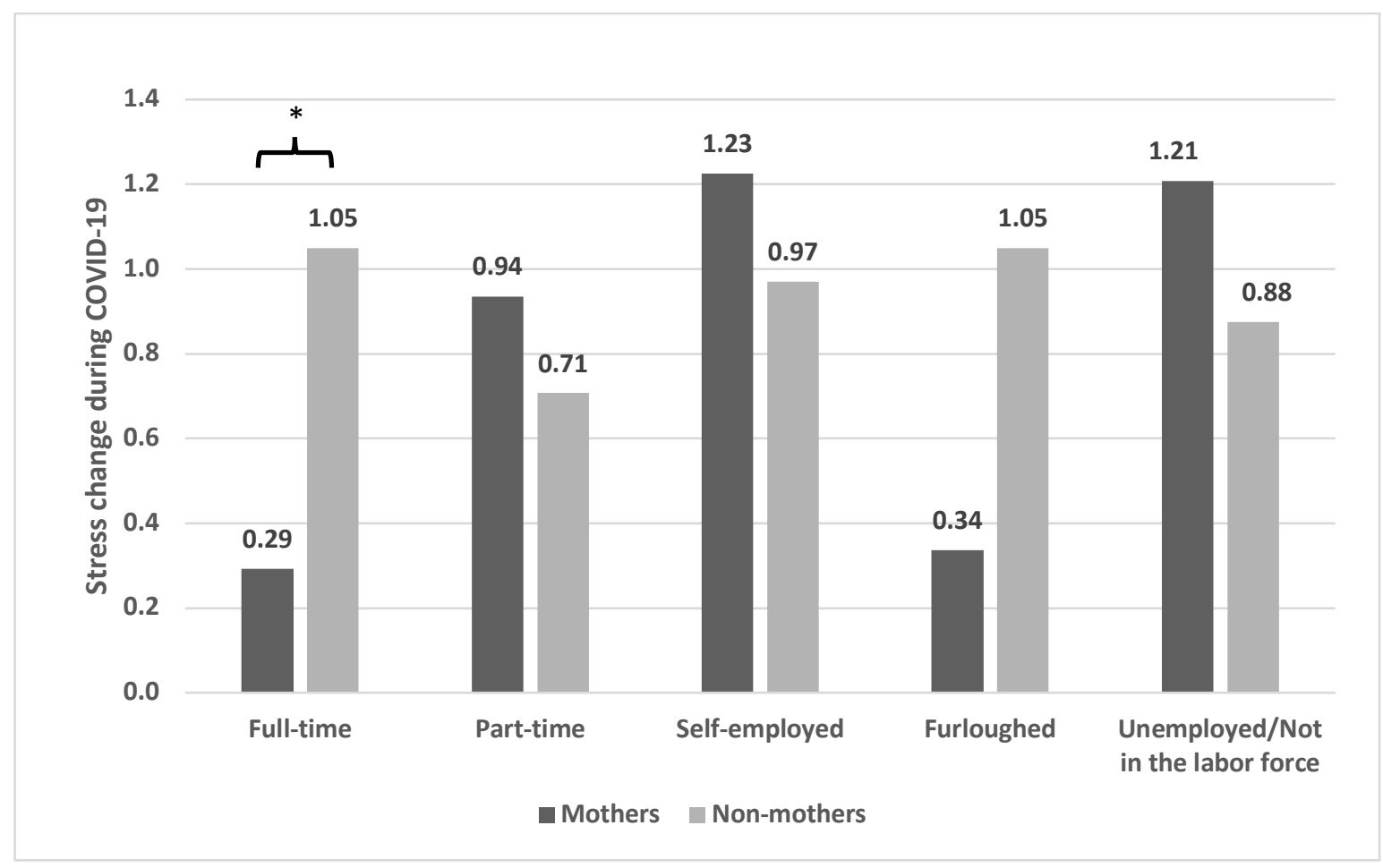

Note: Results present predicted probabilities from OLS models (Model 2 in Table 3 ). ${ }^{*} \mathrm{p}<.05$, $* * \mathrm{p}<.01, * * * \mathrm{p}<.001$. 
Figure 3. Predicted Means of Stress Level Changes After the COVID-19 Outbreak by Women's Mothering Status and the Change of Work Hours after the COVID-19 Outbreak ( $N=1,505$, unweighted).

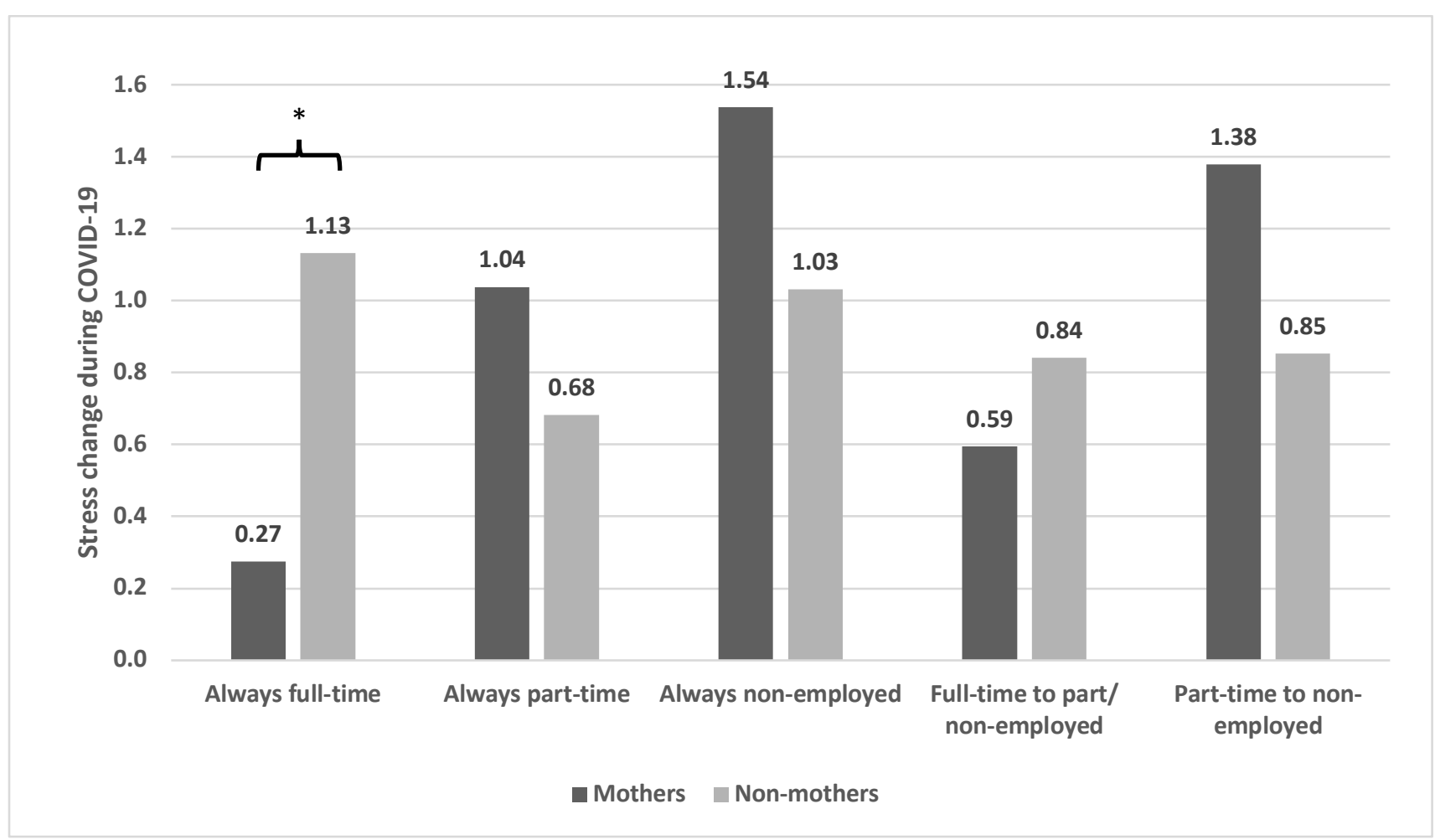

Note: Results present predicted probabilities from OLS models (Model 3 in Table 3 ). ${ }^{*} \mathrm{p}<.05, * * \mathrm{p}<.01$, $* * * \mathrm{p}<.001$. 
Appendix A. Comparisons between the sample of unweighted and weighted Assessing the Social Consequences of COVID-19 (ASCC) study and the 2018 General Social Survey (GSS).

\begin{tabular}{|c|c|c|c|c|c|c|}
\hline & \multicolumn{2}{|c|}{ Unweighted ASCC } & \multicolumn{2}{|c|}{ Weighted ASCC } & \multicolumn{2}{|c|}{ GSS } \\
\hline & Non-mothers & Mothers & Non-mothers & Mothers & Non-mothers & Mothers \\
\hline Age & $\begin{array}{l}28.06 \\
(7.50)\end{array}$ & $\begin{array}{l}34.86 \\
(6.49)\end{array}$ & $\begin{array}{l}32.39 \\
(9.88)\end{array}$ & $\begin{array}{l}35.88 \\
(5.46)\end{array}$ & $\begin{array}{c}32.53 \\
(8.71)\end{array}$ & $\begin{array}{l}35.44 \\
(8.46)\end{array}$ \\
\hline \multicolumn{7}{|l|}{ Race $(\%)$} \\
\hline White & 60.4 & 73.2 & 63.2 & 69.5 & 62.9 & 69.9 \\
\hline Black & 8.5 & 5.8 & 21.1 & 13.1 & 21.5 & 12.8 \\
\hline Others & 31.1 & 21.1 & 15.7 & 17.4 & 15.6 & 17.3 \\
\hline Married (\%) & 18.3 & 68.0 & 40.7 & 58.9 & 40.7 & 58.9 \\
\hline Years of education & $\begin{array}{l}15.03 \\
(2.17)\end{array}$ & $\begin{array}{l}15.10 \\
(2.13)\end{array}$ & $\begin{array}{l}14.30 \\
(2.32)\end{array}$ & $\begin{array}{l}14.30 \\
(1.51)\end{array}$ & $\begin{array}{l}14.09 \\
(2.69)\end{array}$ & $\begin{array}{l}13.70 \\
(3.01)\end{array}$ \\
\hline \multicolumn{7}{|c|}{ Pre-COVID weekly work hours (\%) } \\
\hline 35 or more & 48.4 & 54.5 & 52.7 & 47.3 & 51.8 & 46.8 \\
\hline $1-34$ & 32.8 & 28.0 & 14.9 & 23.3 & 14.8 & 23.0 \\
\hline 0 & 18.8 & 17.4 & 32.4 & 29.5 & 33.4 & 30.2 \\
\hline \multicolumn{7}{|l|}{ Household income (\%) } \\
\hline Lower than 20k & 16.1 & 11.2 & 16.7 & 15.3 & 16.8 & 15.1 \\
\hline $20 \mathrm{k}-60 \mathrm{k}$ & 38.3 & 35.3 & 37.9 & 38.3 & 38.5 & 39.0 \\
\hline $60 \mathrm{k}-100 \mathrm{k}$ & 23.7 & 33.4 & 25.4 & 25.0 & 25.0 & 24.8 \\
\hline Higher than 100k & 22.0 & 20.0 & 20.0 & 21.5 & 19.7 & 21.2 \\
\hline $\mathrm{N}$ & 1,140 & 365 & 1,140 & 365 & 390 & 294 \\
\hline
\end{tabular}


Appendix B. Predicted Stress Levels Before and During the COVID-19, and the Change of Stress Levels After the COVID-19 Outbreak by Mothering Status ( $N=1,505$, weighted).

\begin{tabular}{lccc}
\hline & Model 1 & Model 2 & Model 3 \\
\hline \multirow{2}{*}{ Mothers (ref. non-mothers) } & Pre-COVID & During COVID & Change \\
\cline { 2 - 4 } & 0.321 & -0.075 & -0.456 \\
Pre-COVID employment status (ref. full-time) & $(0.300)$ & $(0.348)$ & $(0.283)$ \\
Part time & & & \\
& -0.282 & -0.656 & -0.024 \\
Self-employed & $(0.340)$ & $(0.437)$ & $(0.350)$ \\
& $-0.826^{*}$ & -0.737 & 0.253 \\
Furloughed & $(0.331)$ & $(0.712)$ & $(0.645)$ \\
& -0.374 & $-3.104^{* *}$ & $-2.511^{*}$ \\
Unemployed/Not in the labor force & $(0.677)$ & $(1.186)$ & $(1.078)$ \\
& $-0.925^{*}$ & -0.235 & $0.836+$ \\
During-COVID employment status (ref. full-time) & $(0.465)$ & $(0.581)$ & $(0.460)$ \\
Part time & & & -0.116 \\
Self-employed & & 0.413 & $(0.362)$ \\
Furloughed & & $(0.494)$ & 0.027 \\
& & 0.076 & $(0.732)$ \\
Unemployed/Not in the labor force & & $(0.707)$ & -0.220 \\
& & $-1.092^{*}$ & $(0.418)$ \\
Constant & & $(0.481)$ & -0.165 \\
R-squared & -0.140 & $(0.422)$ \\
\hline
\end{tabular}

Note: Results present regression coefficients from OLS models. Standard errors in parentheses. All covariates were also controlled, but we omit the coefficients to conserve space. ${ }^{*} \mathrm{p}<.05,{ }^{* *} \mathrm{p}<.01,{ }^{* * *}$ $\mathrm{p}<.001,+\mathrm{p}<.10$. 
Appendix C. Predicted Stress Level Changes Following the COVID-19 Outbreak by Mothering Status and Employment Status ( $N=1,505$, weighted).

\begin{tabular}{|c|c|c|c|}
\hline & Model 1 & Model 2 & Model 3 \\
\hline Mothers (ref. non-mothers) & $\begin{array}{c}-1.411 * * * \\
(0.407)\end{array}$ & $\begin{array}{c}-1.133^{* *} \\
(0.416)\end{array}$ & $\begin{array}{c}-1.436^{* * *} \\
(0.418)\end{array}$ \\
\hline \multicolumn{4}{|l|}{ Weekly work hours (ref. 35-40) } \\
\hline $1-34$ & $\begin{array}{c}-0.718^{*} \\
(0.314)\end{array}$ & & \\
\hline ( & $\begin{array}{c}-0.432 \\
(0.311)\end{array}$ & & \\
\hline \multicolumn{4}{|l|}{ Mothers*Weekly work hours } \\
\hline Mother*1-34 & $\begin{array}{c}1.803 * * * \\
(0.521)\end{array}$ & & \\
\hline Mother*0 & $\begin{array}{c}1.344^{* *} \\
(0.448)\end{array}$ & & \\
\hline \multicolumn{4}{|l|}{ Employment status (ref. full-time) } \\
\hline Part-time & & $\begin{array}{c}-0.765^{*} \\
(0.360)\end{array}$ & \\
\hline Self-employed & & $\begin{array}{l}-0.172 \\
(0.394)\end{array}$ & \\
\hline Furloughed/Stay at home & & $\begin{array}{l}-0.247 \\
(0.457)\end{array}$ & \\
\hline Unemployed/Not in the labor force & & $\begin{array}{l}-0.320 \\
(0.367)\end{array}$ & \\
\hline \multicolumn{4}{|l|}{ Mothers*Employment status } \\
\hline Mother*Part-time & & $\begin{array}{l}1.426^{*} \\
(0.599)\end{array}$ & \\
\hline Mother*Self-employed & & $\begin{array}{c}0.786 \\
(0.707)\end{array}$ & \\
\hline Mother*Furloughed & & $\begin{array}{l}-0.003 \\
(0.755)\end{array}$ & \\
\hline Mother* Unemployed/Not in the labor force & & $\begin{array}{l}1.192^{*} \\
(0.475)\end{array}$ & \\
\hline \multicolumn{4}{|l|}{ Employment change (ref. always full-time) } \\
\hline Always part-time & & & $\begin{array}{c}-1.191 * * \\
(0.368)\end{array}$ \\
\hline Always non-employed & & & $\begin{array}{c}0.002 \\
(0.416)\end{array}$ \\
\hline Full-time to part-time/non-employed & & & $\begin{array}{c}-0.383 \\
(0.335)\end{array}$ \\
\hline Part-time to non-employed & & & $\begin{array}{l}-0.212 \\
(0.393)\end{array}$ \\
\hline \multicolumn{4}{|l|}{ Mothers*Employment change } \\
\hline Mother*Always Part-time & & & $\begin{array}{c}2.323 * * * \\
(0.571)\end{array}$ \\
\hline Mother*Always Non-employed & & & $\begin{array}{c}1.860 * * * \\
(0.529)\end{array}$ \\
\hline Mother*Full-time to part-time/non-employed & & & $\begin{array}{c}0.914 \\
(0.546)\end{array}$ \\
\hline Mother*Part-time to non-employed & & & $\begin{array}{l}1.220^{*} \\
(0.600)\end{array}$ \\
\hline Constant & $\begin{array}{l}2.193^{*} \\
(0.915)\end{array}$ & $\begin{array}{l}2.232^{*} \\
(0.954)\end{array}$ & $\begin{array}{l}1.629+ \\
(0.963)\end{array}$ \\
\hline R-squared & 0.125 & 0.120 & 0.142 \\
\hline
\end{tabular}

Note: Results present regression coefficients from OLS models. Standard errors in parentheses. All covariates were controlled, but we omit the coefficients to conserve space. ${ }^{*} \mathrm{p}<.05,{ }^{* *} \mathrm{p}<.01,{ }^{* * *} \mathrm{p}$ $<.001,+\mathrm{p}<.10$. 
Appendix D. Predicted Stress Level Changes After the COVID-19 Outbreak by MotheringEmployment Status ( $N=1,505$, unweighted).

\begin{tabular}{|c|c|c|c|}
\hline & Model 1 & Model 2 & Model 3 \\
\hline \multicolumn{4}{|c|}{ Motherhood \& weekly work hours (ref. mothers 35 or more) } \\
\hline Mothers 1-34 & $\begin{array}{c}0.663 * \\
(0.331)\end{array}$ & & \\
\hline Mothers 0 & $\begin{array}{l}0.774^{*} \\
(0.317)\end{array}$ & & \\
\hline Non-mothers 35 or more & $\begin{array}{l}0.804^{*} \\
(0.329)\end{array}$ & & \\
\hline Non-mothers 1-34 & $\begin{array}{c}0.498 \\
(0.335)\end{array}$ & & \\
\hline Non-mothers 0 & $\begin{array}{l}0.586+ \\
(0.342)\end{array}$ & & \\
\hline \multicolumn{4}{|l|}{ Motherhood \& employment status (ref. mothers full-time) } \\
\hline Mothers part-time & & $\begin{array}{l}0.660+ \\
(0.376)\end{array}$ & \\
\hline Mothers self-employed & & $\begin{array}{l}0.909+ \\
(0.489)\end{array}$ & \\
\hline Mothers furloughed & & $\begin{array}{c}0.069 \\
(0.553)\end{array}$ & \\
\hline Mothers unemployed/not in the labor force & & $\begin{array}{c}0.910 * * \\
(0.324)\end{array}$ & \\
\hline Non-mothers full-time & & $\begin{array}{l}0.743 * \\
(0.321)\end{array}$ & \\
\hline Non-mothers part-time & & $\begin{array}{c}0.417 \\
(0.353)\end{array}$ & \\
\hline Non-mothers self-employed & & $\begin{array}{l}0.656+ \\
(0.380)\end{array}$ & \\
\hline Non-mothers furloughed & & $\begin{array}{l}0.755+ \\
(0.391)\end{array}$ & \\
\hline Non-mothers unemployed/not in the labor force & & $\begin{array}{c}0.563 \\
(0.346)\end{array}$ & \\
\hline \multicolumn{4}{|c|}{ Motherhood \& employment change (ref. mothers always full-time) } \\
\hline Mothers always part-time & & & $\begin{array}{l}0.753+ \\
(0.404)\end{array}$ \\
\hline Mothers always not-employed & & & $\begin{array}{c}1.260 * * \\
(0.448)\end{array}$ \\
\hline Mothers full-time to part-time/non-employed & & & $\begin{array}{c}0.339 \\
(0.340)\end{array}$ \\
\hline Mothers part-time to non-employed & & & $\begin{array}{l}1.099^{*} \\
(0.430)\end{array}$ \\
\hline Non-mothers always full-time & & & $\begin{array}{l}0.848^{*} \\
(0.334)\end{array}$ \\
\hline Non-mothers always part-time & & & $\begin{array}{c}0.400 \\
(0.359)\end{array}$ \\
\hline Non-mothers always not-employed & & & $\begin{array}{l}0.751+ \\
(0.436)\end{array}$ \\
\hline Non-mothers full-time to part-time/non-employed & & & $\begin{array}{c}0.545 \\
(0.345)\end{array}$ \\
\hline Non-mothers part-time to non-employed & & & $\begin{array}{c}0.557 \\
(0.374)\end{array}$ \\
\hline Constant & $\begin{array}{c}0.857 \\
(0.781)\end{array}$ & $\begin{array}{c}0.838 \\
(0.781)\end{array}$ & $\begin{array}{c}0.697 \\
(0.835)\end{array}$ \\
\hline R-squared & 0.053 & 0.056 & 0.060 \\
\hline
\end{tabular}

Note: Results present regression coefficients from OLS models. Standard errors in parentheses. All covariates were controlled, but we omit the coefficients to conserve space. ${ }^{*} \mathrm{p}<.05, * * \mathrm{p}<.01, * * * \mathrm{p}<.001,+\mathrm{p}<.10$. 
Appendix E. Predicted Means of Women's Pre- and During-COVID Stress Levels by Mothering and Employment Statuses ( $N=1,505$, unweighted).

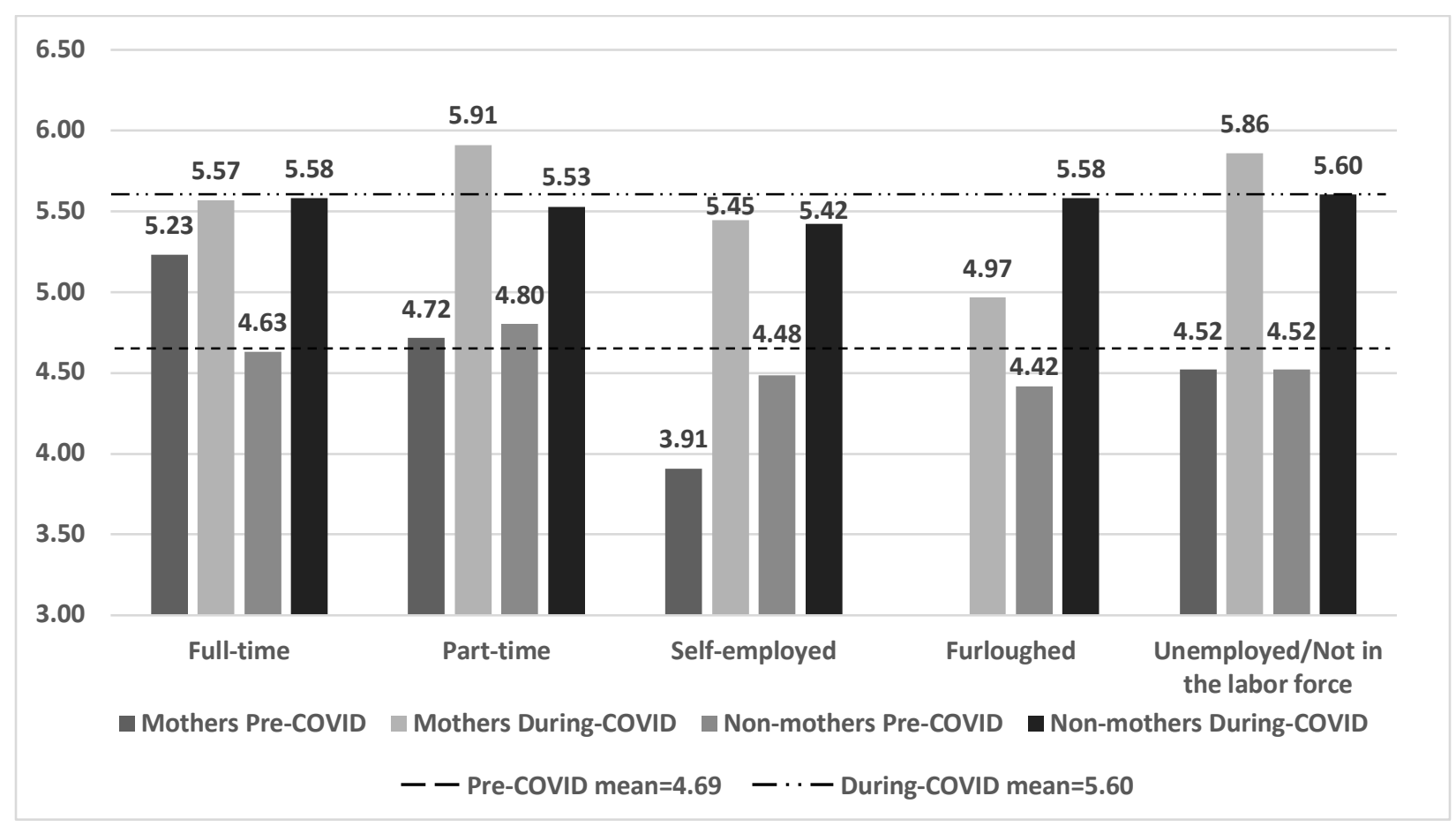

